\title{
Near Infrared Light Responsive Hybrid Nanoparticles for Synergistic Therapy
}

\author{
Yan Liang, ${ }^{a}$ Wenxia Gao, ${ }^{*}$ Xinyu Peng, ${ }^{a}$ Xin Deng, ${ }^{a}$ Changzhen Sun, ${ }^{a}$ Huayue Wu, ${ }^{\mathrm{b}}$ Bin He ${ }^{* a}$
}

${ }^{a}$ National Engineering Research Center for Biomaterials, Sichuan University, Chengdu 610064 China

${ }^{\mathrm{b}}$ College of Chemistry and Materials Engineering, Wenzhou University, Wenzhou 325027, China

* To whom correspondence should be addressed, E-mail: wenxiag@wzu.edu.cn (W. Gao); bhe@scu.edu.cn (B. He)

\begin{abstract}
A near

infrared

(NIR)

light responsive

chromophore

7-(diethylamino)-4-(hydroxymethyl)-2H-chromen-2-one (DEACM) was synthesized and incorporated to $\beta$-cyclodextrins with cRGD functionalized poly(ethylene glycol), the amphiphiles were coordinated with Au nanorods and nanoparticles to load anticancer drug doxorubicin (DOX) for fabricating hybrid nanoparticles. The $\pi$ - $\pi$ stacking interaction between DEACM and DOX was formed in the hybrid nanoparticles, which contributed to the high drug loading content. The $\mathrm{Au}$ nanorods and nanoparticles enhanced the photosolvolysis of DEACM under the irradiation of NIR with $808 \mathrm{~nm}$ wavelength and triggered the accelerated drug release from the nanoparticles. The drug loaded hybrid nanoparticles with NIR irradiation exhibited efficient inhibition effect on the proliferation of $4 \mathrm{~T} 1$ breast cancer cells in vitro. The in vivo anticancer activity study on breast cancer bearing mice revealed that the hybrid nanoparticles containing Au nanorods exhibited excellent anticancer activity under the irradiation of $808 \mathrm{~nm}$ wavelength NIR with $800 \mathrm{~mW}$.
\end{abstract}

Keywords: NIR-responsive, photosolvolysis, hybrid nanoparticles, Au nanorods, synergistic therapy

\section{Introduction}

Nanoparticles for anticancer drug delivery have been attracted great interest for cancer chemotherapy due to the enhanced permeation and retardant (EPR) effect of blood vessels in tumors.[1, 2] The microenvironment of tumors is different from normal tissues,[3-5] which inspired all kinds of stimuli-sensitive nanoparticles for chemotherapy. Taking the advantages of stimuli of weak acidity, high concentrated matrix metalloproteinases (MMPs), glutathione (GSH) and reactive oxygen species (ROS) in tumors, the $\mathrm{pH}$, enzyme, redox, and ROS responsive nano drug delivery systems were extensively studied.[6-10] These intrinsic stimuli sensitive nanoparticles triggered drug release passively with contact modes to exhibit optimistic and effective treatment of cancers. Other exogenous stimuli such as light, temperature, magnetic field exerted active and remote control of drug release via noncontact mode.[6, 11-13] 
Laser has been used in cancer therapy via activating the photosensitizers to produce single oxygen and kill cancer cells, which was called photodynamic therapy (PDT).[14-16] The penetration of laser in tissues is weak due to its short wavelength, thus, the PDT is limited to epidermal diseases. The wavelength of near infrared (NIR) light is in the range from $700 \mathrm{~nm}$ to $1000 \mathrm{~nm}$, the long wavelength of NIR light penetrated deeperin human tissues and resulted in less detrimental to healthy cells with the reduced absorption and scattering of NIR in water and biological substances.[17, 18] Gold nanoparticles and nanorods have been reported to absorb near infrared light to transfer heat efficiently for photothermal therapy of cancers.[19, 20] However, the surface coating of gold nanoparticles and nanorods to improve their biocompatibility would weaken the therapeutic efficacy.[21, 22]

Polymers with photochromic groups, which was induced by light to change the architectures, have been exploited as light-sensitive polymers.[23] The wavelength of light to trigger the reversible photoisomerization or irreversible photocleavage of light sensitive polymers was located in the region of UV or visible light.[24, 25] Recently, the chromophore of a coumarin derivative was explored to design photocontrollable BCP micelles.[26, 27] Althought the irradiation of NIR light could cleave the chemical bond in the coumarin derivative, the lightresponsive BCP micelles were mainly activated by UV and visible light to avoid inefficient two-photon absorption to weaken the cleavage efficiency.[28]

Rational design of stimuli-sensitive nanocarriers is important to fabricate nanomedicines with promising chemotherapeutic efficiency. Polymeric micelles with $\pi-\pi$ conjugated moieties including coumarin derivatives as hydrophobic segments have been proved to enhance drug loading content via the formation of $\pi-\pi$ stacking interaction between anticancer drugs and micelles.[29] These $\pi-\pi$ conjugated moieties modified polymeric micelles exhibited significant anticancer activity both in vitro and in vivo. Other than the interactions between drugs and carriers, the cage of cyclodextrin (CD) is also an effective strategy to load anticancer drugs efficiently, the diverse functionalizations of CDs have been reported in anticancer drug delivery.[30]

In this paper, a NIR light sensitive hybrid nanoparticles for cancer chemotherapy was fabricated as shown in Figure 1. A coumarin derivative chromophore moiety named 7-(diethylamino)-4-(hydroxymethyl)- $2 H$-chromen-2-one (DEACM) was immobilized on $\beta$-CDs, the bond in DEACM was cleavable under the irradation of NIR with the wavelength of $808 \mathrm{~nm}$. Gold nanorods were cooperated with $\beta$-CDs to promote the NIR adsorption. Poly(ethylene glycol) (PEG) functionalized with clycle RGD peptide (cRGD) was linked to $\beta$-CDs for active targeting and long circulation. Anticancer drug doxorubicin (DOX) was loaded in the self-assembly $\beta$-CDs amphiphiles based hydrid nanoparticles. The NIR light irradiation activated the gold nanorods and it accelerated the photosolvolysis of DEACM to trigger the rapid release of DOX. Both in vitro and in vivo anticancer activities of the drug loaded hybrid nanoparticles with NIR sensitivity were investigated. 


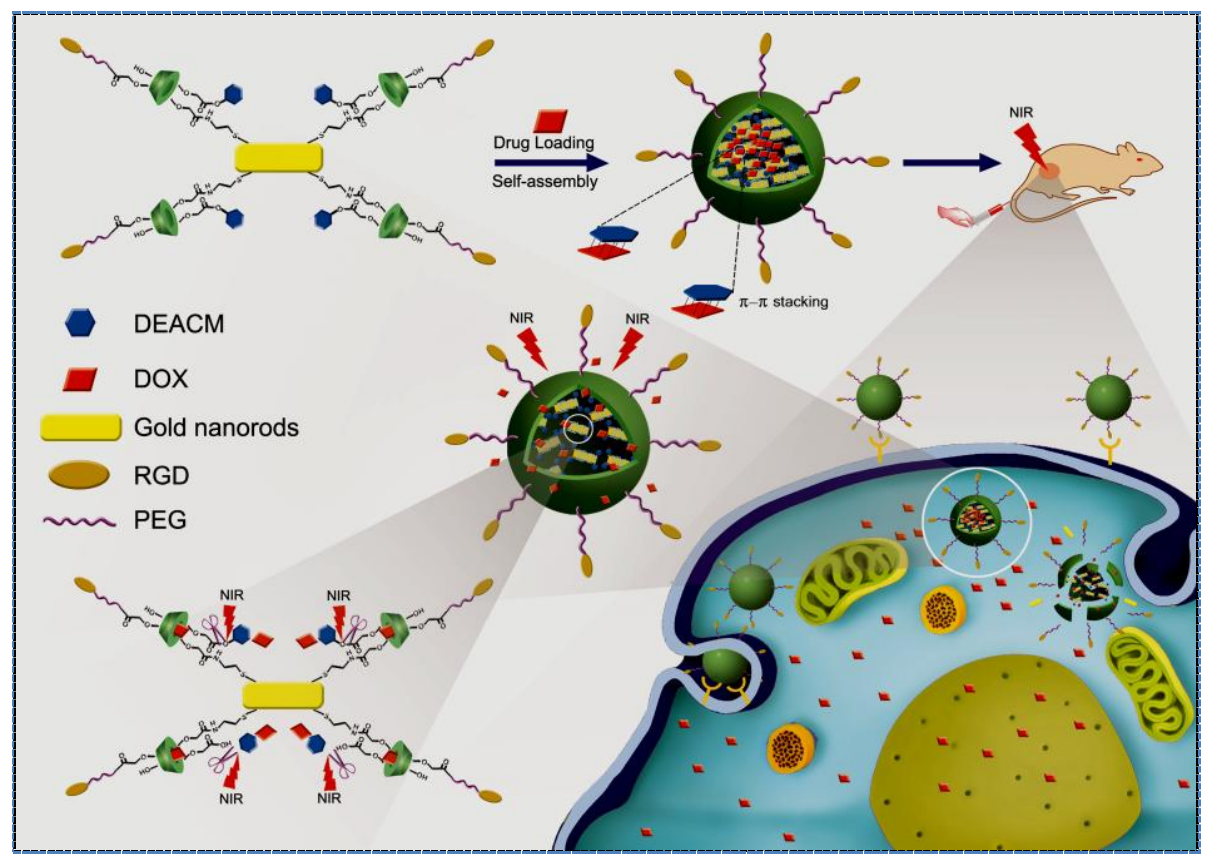

Figure 1. The schematic illustration of NIR-responsive hybrid nanoparticles for cancer therapy.

\section{Materials and methods}

Materials

$\beta$-Cyclodextrin and monochloroacetic acid was purchased from Sinopharm Chemical Reagent. 1-ethyl-(3-dimethyllaminopropyl) carbodiiehydrochlide (EDC·HCl), N-hydroxysuccinimide (NHS), 1-hydroxy-benzotriazole monohydrate (HOBT), and cyclo(RGDfC-SH) were purchased from GL Biochem. Ltd. (Shanghai, China). Methoxy poly(ethylene glycol) (mPEG, Mw=2000 $\mathrm{g} / \mathrm{mol}$ ), poly(ethylene glycol) (PEG, $\mathrm{Mw}=2000 \mathrm{~g} / \mathrm{mol}$ ), and 3-maleimidopropionic acid (MAL) were purchased from Sigma-Aldrich Co. Ltd. N,N-diisopropylethylamine (DIEA), 7-Diethylamino-4-methylcoumarin, 2-aminoethanethiol, methyl benzenesulfonyl ( $\mathrm{TsCl}$ ), $\mathrm{HAuCl}_{4} \cdot 3 \mathrm{H}_{2} \mathrm{O}$, cetyltrimethylammonium bromide (CTAB), ascorbic acid, $\mathrm{NaBH}_{4}$, and triethylamine (TEA) were purchased from Asta Tech (Chengdu) Biopharm. Co. Ltd. Doxorubicin hydrochloride (DOX $\cdot \mathrm{HCl}$, Zhejiang Hisun Pharmaceutical, China) was deprotonated according to the method previously reported.[31] All the solvents were purchased from Chengdu Kelong Chemical Co. (China) and purified before used. Dulbecco's modified Eagle's medium (DMEM), $100 \mathrm{x}$ mycillin, fetal bovine serum (FBS) and cell counting kit-8 (CCK-8) were purchased from HyClone Inc. and used for cytotoxicity test.

\section{Characterizations}

The ${ }^{1} \mathrm{H}$ NMR spectra were performed on Bruker Avance II NMR spectrometer at $400 \mathrm{MHz}$ using tetramethylsilane as the internal standard. The measurements of size and size distribution of the nanoparticles were carried out using a dynamic light scattering (DLS) spectrometer (Malvern ZetasizerNano ZS). Scanning electron microscope (SEM, S4800, Hitachi Ltd, Tokyo, Japan) and transmission electron microscopy (TEM, JEM-100CX-JEOL, Japan) were employed to observe the morphology of the nanoparticles. The lyophilized nanoparticles were redispersed in distilled 
water and dropped onto silicon pellet, the samples were dried overnight at room temperature for SEM. The TEM samples were prepared by dipping a copper grid with Formvar film into the freshly prepared nanoparticles solution. The copper grid was dried overnight at room temperature. UV-vis absorption (Specord 200 PLUS) and Fluorescence spectra (F-7000, Hitachi, Japan) were used to measure the drug loading content, releasing profile and $\pi-\pi$ interaction between drug and carriers.

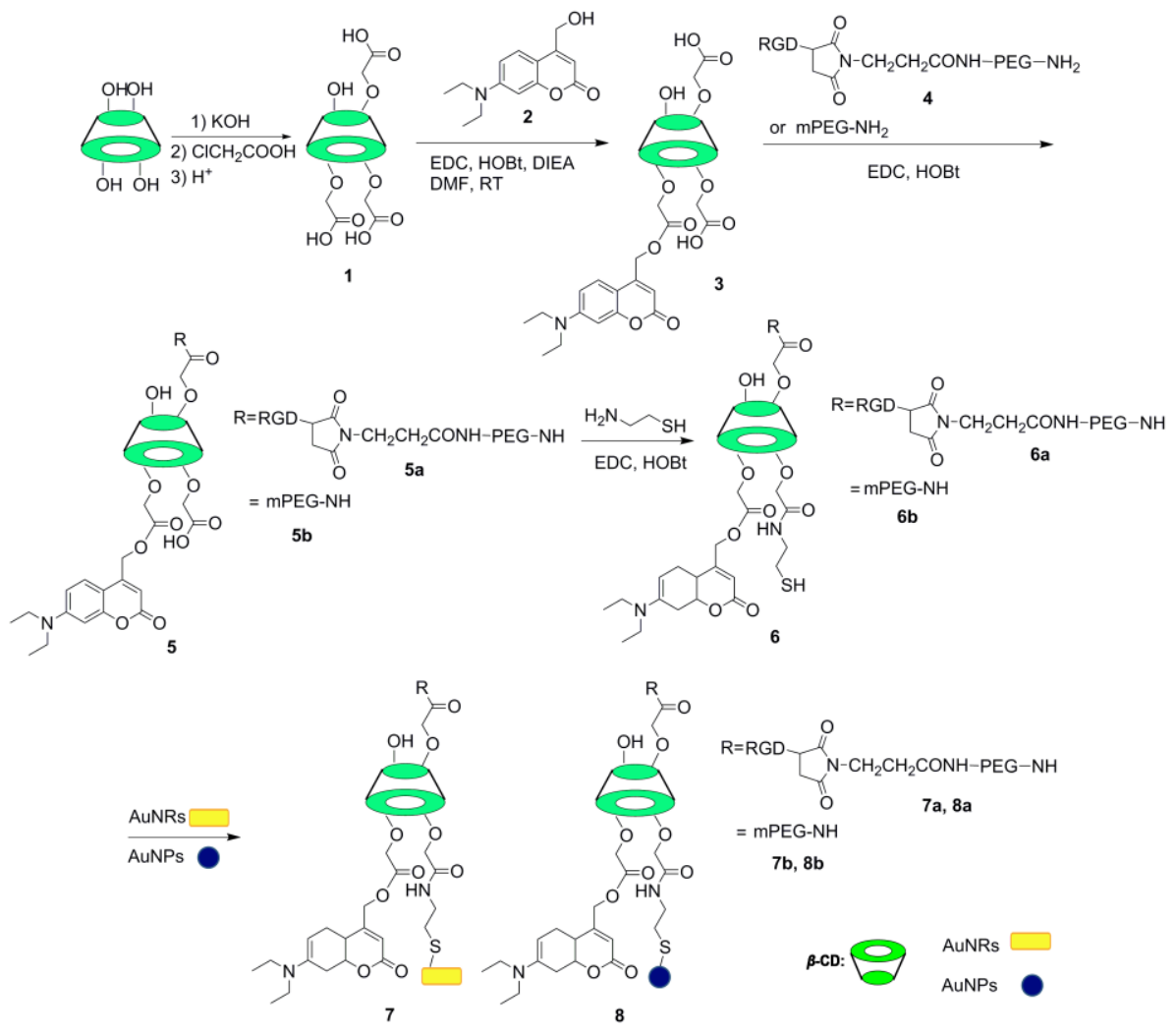

Scheme 1. The synthesis of NIR-responsive drug carrier.

\section{Synthesis of compound 1}

Carboxymethyl $\beta$-cyclodextrin was prepared according to the method previously reported.[32] $\beta$-cyclodextrin $(7.1 \mathrm{mmol}$ ) was dissolved in $60 \mathrm{~mL}$ of $5 \%(\mathrm{w} / \mathrm{v}) \mathrm{KOH}$ solution and $0.12 \mathrm{~mol}$ of monochloroacetic acid was added. The mixtrure was vigorously stirred at $80{ }^{\circ} \mathrm{C}$ for $10 \mathrm{~h}$. The solution was cooled to room temperature and the $\mathrm{pH}$ value was carefully adjusted to about 6.0 with $6 \mathrm{M} \mathrm{H}_{2} \mathrm{SO}_{4}$. This solution was poured into $200 \mathrm{~mL}$ ethanol. The precipitate was washed with ethanol and dried under vacuum overnight. ${ }^{1} \mathrm{H}$ NMR (400 MHz, DMSO- $d_{6}$ ): $\delta=5.83,5.80,4.83$, 4.49, 3.74-3.3, 4.4 (s, $-\mathrm{CH}_{2} \mathrm{COOH}, 2 \mathrm{H}$ ). The degree of substitution ( $\mathrm{DS}=3$ ) of carboxymethyl on $\beta$-CD was calculated from the peak area at $\delta=4.4$ of the carboxymethyl(s, $\left.-\mathrm{CH}_{2} \mathrm{COOH}, 2 \mathrm{H}\right)$ with the comparison of $\delta=4.83$ attributed to the $-\mathrm{CH}-$ proton of $\beta$ - $\mathrm{CD}$ (yield $=73.5 \%$ ).

Synthesis of compound 2

7-(diethylamino)-4-(hydroxymethyl)- $2 \mathrm{H}$-chromen-2-one (DEACM) was synthesized as following procedure. $\mathrm{SeO}_{2}(6.7 \mathrm{~g})$ and 7-diethylamino-4-methylcoumarin $(9.95 \mathrm{~g})$ were suspended in 120 
$\mathrm{mL}$ p-xylene, the mixture was refluxed under vigorous stirring in nitrogen atmosphere. After stirred for $16 \mathrm{~h}$, the mixture was filtered and concentrated under reduced pressure. The dark brown residual oil was dissolved in THF/ethanol (v/v 1:1) (150 mL), sodium borohydride (2.2 $\mathrm{g})$ was added, and the solution was stirred at room temperature for $4 \mathrm{~h}$. The suspension was carefully neutralized with $1 \mathrm{M} \mathrm{HCl}$, the solution was concentrated and dissolved in dichloromethane. The organic phase was extracted with $\mathrm{K}_{2} \mathrm{CO}_{3}$ aqueous solution for three times, dried over $\mathrm{Na}_{2} \mathrm{SO}_{4}$ and concentrated. The raw product was purified by column chromatography $(\mathrm{n}-\mathrm{Hexane} / \mathrm{EtOAc}=2 / 1)$ to get brown solid with the yield of $20.2 \%$. ${ }^{1} \mathrm{H}$ NMR $\left(400 \mathrm{MHz}, \mathrm{CDCl}_{3}\right): \delta=7.23$ (d, -CHCHC-, $1 \mathrm{H}), 6.50(\mathrm{~d},-\mathrm{CCHCH}-, 1 \mathrm{H}), 6.42(\mathrm{~s},-\mathrm{CCHC}-1 \mathrm{H}), 6.20(\mathrm{~s},-\mathrm{CCHCO}-, 1 \mathrm{H}), 4.76\left(\mathrm{~s},-\mathrm{CCH}_{2} \mathrm{OH}\right.$, $2 \mathrm{H}), 3.32\left(\mathrm{~m}, \mathrm{CH}_{3} \mathrm{CH}_{2} \mathrm{~N}-, 2 \mathrm{H}\right), 1.14\left(\mathrm{t}, \mathrm{CH}_{3} \mathrm{CH}_{2^{-}}, 3 \mathrm{H}\right) .{ }^{13} \mathrm{C} \mathrm{NMR}\left(100 \mathrm{MHz}, \mathrm{CDCl}_{3}\right): \delta=161.6$, 155.1, 153.7, 149.3, 123.5, 107.6, 104.4, 104.4, 96.7, 59.9,43.7, 11.4. MS (EI): 248.0 [M+].

Synthesis of compound 3

Carboxymethyl $\beta$-cyclodextrin (0.5 g, $0.32 \mathrm{mmol}$ ), 7-(diethylamino)-4-(hydroxymethyl)$2 \mathrm{H}$-chromen-2-one (DEACM) $(0.32 \mathrm{~g}, 1.28 \mathrm{mmol}), \mathrm{EDC} \cdot \mathrm{HCl}(0.5 \mathrm{~g}, 2.56 \mathrm{mmol})$ and $\mathrm{HOBt}(0.35$ $\mathrm{g}, 2.56 \mathrm{mmol})$ were dissolved in $50 \mathrm{~mL}$ of DMF. DIEA ( $0.64 \mathrm{~mL}, 3.84 \mathrm{mmol})$ was injected into the solution. The mixture was stirred at room temperature for $48 \mathrm{~h}$. The solvent was evaporated and the crude product was received. After precipitated in trichloromethane for four times, the compound 3 was received. ${ }^{1} \mathrm{H}$ NMR $\left(400 \mathrm{MHz}, \mathrm{CDCl}_{3}\right): \delta=7.32$ (-CHCHC-, $\left.1 \mathrm{H}\right), 6.67$ $(-\mathrm{CCHCH}-, \quad 1 \mathrm{H}), 6.52(-\mathrm{CCHC}-1 \mathrm{H}), 6.20(-\mathrm{CCHCO}-1 \mathrm{H}), 5.75(\beta-\mathrm{CD}, \mathrm{OH}, 2 \mathrm{H}), 4.85$ (- $\left.\mathrm{CH}_{2} \mathrm{OOC}\right), 4.68(\beta-\mathrm{CD}, \mathrm{CH}, 1 \mathrm{H}), 4.50\left(-\mathrm{CH}_{2} \mathrm{COOH}, 2 \mathrm{H}\right), 3.64-3.0\left(\beta-\mathrm{CD}, \mathrm{C}_{2} \mathrm{H}-\mathrm{C}_{6} \mathrm{H}\right.$; $\left.-\mathrm{CH}_{2} \mathrm{CH}_{3}\right)$, $1.12\left(\mathrm{CH}_{3}, 6 \mathrm{H}\right)$.

Synthesis of compound 4

PEG2000 (5.0 g, $2.5 \mathrm{mmol})$ and $\mathrm{TsCl}(1.91 \mathrm{~g}, 10 \mathrm{mmol})$ were dissolved in $70 \mathrm{~mL}$ of $\mathrm{CH}_{2} \mathrm{Cl}_{2}$ in an ice bath. TEA $(2.78 \mathrm{~mL}, 20 \mathrm{mmol})$ dissolved in $10 \mathrm{~mL}$ of $\mathrm{CH}_{2} \mathrm{Cl}_{2}$ was added dropwise. The mixture was stirred for $24 \mathrm{~h}$. The solution was washed with $0.5 \mathrm{M} \mathrm{HCl}$ and saturated brine for three times, respectively. The organic phase was dried with anhydrous $\mathrm{MgSO}_{4}$ overnight. The filtrate was concentrated and dissolved in $150 \mathrm{~mL}$ of ammonia water. The mixture was stirred for $48 \mathrm{~h}$ at room temperature and extracted with $\mathrm{CH}_{2} \mathrm{Cl}_{2}$ for three times. $1 \mathrm{M} \mathrm{NaOH}(100 \mathrm{~mL})$ was added to the organic phase and stirred for $3 \mathrm{~h}$. The organic phase was washed with saturated brine for three times and dried with anhydrous $\mathrm{MgSO}_{4}$ overnight. The filtrate was concentrated and precipitated in diethylether $(200 \mathrm{~mL})$ to receive $\mathrm{H}_{2} \mathrm{~N}-\mathrm{PEG} 2000-\mathrm{NH}_{2}$.

MAL (93 mg, 0.55mmol), NHS (0.29 g, $2.56 \mathrm{mmol})$, and EDC. $\mathrm{HCl}(0.5 \mathrm{~g}, 2.56 \mathrm{mmol})$ were dissolved in $10 \mathrm{~mL}$ of $\mathrm{CH}_{2} \mathrm{Cl}_{2}$ and stirred at room temperature for $4 \mathrm{~h}$. The mixture was added dropwise to the solution of $\mathrm{H}_{2} \mathrm{~N}-\mathrm{PEG} 2000-\mathrm{NH}_{2}(1.0 \mathrm{~g}, 0.5 \mathrm{mmol})$ in $16 \mathrm{~mL}$ of $\mathrm{CH}_{2} \mathrm{Cl}_{2}$. The mixture was stirred for $48 \mathrm{~h}$. The solvent was evaporated and the crude product was precipitated in cold diethylether to receive MAL-PEG2000- $\mathrm{NH}_{2}$.

Cyclo(RGDfC-SH) (40 mg) was dissolved in $2 \mathrm{~mL}$ DMSO and added dropwise to the solution of MAL-PEG2000- $\mathrm{NH}_{2}(240 \mathrm{mg}$ ) in $8 \mathrm{~mL}$ pyridine. The mixture was stirred at room temperature for $24 \mathrm{~h}$. The solvent was evaporated and the crude product was precipitated in cold diethylether to 
receive RGD-MAL-PEG2000- $\mathrm{NH}_{2}$.

${ }^{1} \mathrm{H}$ NMR of $\mathrm{H}_{2} \mathrm{~N}-\mathrm{PEG}-\mathrm{NH}_{2}\left(400 \mathrm{MHz}, \mathrm{CDCl}_{3}\right): \quad \delta=2.90 \mathrm{ppm}\left(-\mathrm{CH}_{2} \mathrm{CHNH} \mathrm{NH}_{2}, 4 \mathrm{H}\right), 3.40-3.90 \mathrm{ppm}$ (d, - $\left.-\mathrm{OCH}_{2} \mathrm{CH}_{2} \mathrm{O}-, 4 \mathrm{H}\right)$. The peaks at $\delta=3.4-3.9 \mathrm{ppm}$ were assigned to the protons of $-\mathrm{OCH}_{2} \mathrm{CH}_{2}-$ in $\mathrm{H}_{2} \mathrm{~N}-\mathrm{PEG}-\mathrm{NH}_{2}(2 \mathrm{k}$ ), yield $85 \%$, substituted degree ( $\mathrm{SD}=79.4 \%$ ).

${ }^{1} \mathrm{H}$ NMR of MAL-PEG-NH $\mathrm{N}_{2}\left(400 \mathrm{MHz}, \mathrm{CDCl}_{3}\right): \quad \delta=6.71 \mathrm{ppm}(\mathrm{CH}=\mathrm{CH}), 3.84 \mathrm{ppm}, 2.52 \mathrm{ppm}$ (CH2), 3.20-3.80 ppm (-OCH $\left.\mathrm{CH}_{2} \mathrm{O}-\right), 2.85 \mathrm{ppm}\left(-\mathrm{CH}_{2} \mathrm{CHNH}_{2}\right)$, yield $80 \%$, substituted degree $(\mathrm{SD}=68.2 \%)$.

RGD-MAL-PEG2000- $\mathrm{NH}_{2}$ was characterized by the disappearance of typical ${ }^{1} \mathrm{H}$ NMR peaks $\delta=6.71 \mathrm{ppm}$ ascribed to the double bond in maleimide $(\mathrm{CH}=\mathrm{CH})$.

Synthesis of compound 5

mPEG2000- $\mathrm{NH}_{2}\left(0.65 \mathrm{~g}, 0.32 \mathrm{mmol}\right.$ ) or RGD-MAL-PEG2000- $\mathrm{NH}_{2}$ (compound 4, $0.32 \mathrm{mmol}$ ), compound $3(0.5 \mathrm{~g})$, EDC. $\mathrm{HCl}(0.25 \mathrm{~g}, 1.28 \mathrm{mmol})$, and $\mathrm{HOBt}(0.18 \mathrm{~g}, 1.28 \mathrm{mmol})$ were added to $50 \mathrm{~mL}$ of DMF, DIEA $(0.50 \mathrm{~mL}, 3.0 \mathrm{mmol})$ was injected into the solution. The mixture was stirred at room temperature for $72 \mathrm{~h}$. The solvent was evaporated and the crude product was received. After precipitated in cold diethyl ether for four times, the compound $5 \mathrm{a}$ of RGD-PEG-NH ${ }_{2}-\beta-C D-C M$ or compound $5 b$ of mPEG- $\beta$-CD-CM was received.

Compound 5a (RGD-PEG- $\beta$-CD-CM) ${ }^{1} \mathrm{H}$ NMR (400 MHz, $\mathrm{CDCl}_{3}$ ): $\delta=7.20-7.55$ (-CH-, phenyl, RGD), 7.32 (-CHCHC-, 1H), 6.67 (-CCHCH-, 1H), 6.52 (-CCHC-, 1H), 6.20 (-CCHCO-, 1H), 5.75 ( $\beta-\mathrm{CD}, \mathrm{OH}, 2 \mathrm{H}), 4.85$ (- $\left.\mathrm{CH}_{2} \mathrm{OOC}\right), 4.11-4.70\left(\mathrm{CH}_{2}, \mathrm{RGD} ; \beta-\mathrm{CD}, \mathrm{CH}, 1 \mathrm{H} ;-\mathrm{CH}_{2} \mathrm{COOH}, 2 \mathrm{H}\right)$, 3.80-2.90 (PEG, - $\left.\mathrm{OCH}_{2} \mathrm{CH}_{2} \mathrm{O}-; \beta-\mathrm{CD}, \mathrm{C}_{2} \mathrm{H}-\mathrm{C}_{6} \mathrm{H} ;-\mathrm{CH}_{2} \mathrm{CH}_{3}\right), 1.12\left(\mathrm{CH}_{3}, 6 \mathrm{H}\right)$.

Compound 5b, (mPEG- $\beta$-CD-CM), ${ }^{1} \mathrm{H}$ NMR $\left(400 \mathrm{MHz}, \mathrm{CDCl}_{3}\right): \delta=7.32$ (-CHCHC-, $\left.1 \mathrm{H}\right), 6.67$ $(-\mathrm{CCHCH}-, \quad 1 \mathrm{H}), 6.52(-\mathrm{CCHC}-1 \mathrm{H}), 6.20(-\mathrm{CCHCO}-1 \mathrm{H}), 5.75(\beta-\mathrm{CD}, \mathrm{OH}, 2 \mathrm{H}), 4.85$ (-CH $\left.\mathrm{CH}_{2} \mathrm{OOC}\right), 4.68$ ( $\left.\beta-\mathrm{CD}, \mathrm{CH}, 1 \mathrm{H}\right), 4.50\left(-\mathrm{CH}_{2} \mathrm{COOH}, 2 \mathrm{H}\right), 3.80-2.90\left(\mathrm{PEG},-\mathrm{OCH}_{2} \mathrm{CH} \mathrm{H}_{2} \mathrm{O}-; \beta-\mathrm{CD}\right.$, $\left.\mathrm{C}_{2} \mathrm{H}-\mathrm{C}_{6} \mathrm{H} ;-\mathrm{CH}_{2} \mathrm{CH}_{3}\right), 1.12\left(\mathrm{CH}_{3}, 6 \mathrm{H}\right)$.

Synthesis of compound 6

Compound 5a of RGD-PEG-NH ${ }_{2}-\beta-C D-C M(0.7 \mathrm{~g})$ or compound 5b of mPEG- $\beta$-CD-CM ( $\left.0.6 \mathrm{~g}\right)$, 2-aminoethanethiol (61.6 mg, $0.8 \mathrm{mmol}), \mathrm{EDC} \cdot \mathrm{HCl}(0.2 \mathrm{~g}, 1.0 \mathrm{mmol})$ and $\mathrm{HOBt}(140 \mathrm{mg}, 1.0$ mmol) were dissolved in $50 \mathrm{~mL}$ of DMF. DIEA $(0.2 \mathrm{~mL}, 1.28 \mathrm{mmol})$ was injected into the solution. The mixture was stirred at room temperature for $48 \mathrm{~h}$. The solvent was evaporated and the crude product was precipitated in cold diethyl ether for four times to obtain compound 6a or compound $6 b$.

Compound 6a, ${ }^{1} \mathrm{H}$ NMR (400 MHz, $\mathrm{CDCl}_{3}$ ): $\delta=7.20-7.55$ (-CH-, phenyl, RGD), 7.32 (-CHCHC-, $1 \mathrm{H}), 6.67(-\mathrm{CCHCH}-, 1 \mathrm{H}), 6.52$ (-CCHC-, 1H), 6.20 (-CCHCO-, 1H), $5.75(\beta-\mathrm{CD}, \mathrm{OH}, 2 \mathrm{H}), 4.85$ (- $\left.\mathrm{CH}_{2} \mathrm{OOC}\right), 4.11-4.70\left(\mathrm{CH}_{2}, \mathrm{RGD} ; \beta-\mathrm{CD}, \mathrm{CH}, 1 \mathrm{H} ;-\mathrm{CH}_{2} \mathrm{COOH}, 2 \mathrm{H}\right), 3.80-2.80$ (PEG, $\left.-\mathrm{OCH}_{2} \mathrm{CH}_{2} \mathrm{O}-; \beta-\mathrm{CD}, \mathrm{C}_{2} \mathrm{H}-\mathrm{C}_{6} \mathrm{H} ;-\mathrm{CH}_{2} \mathrm{CH}_{3}\right), 1.12\left(\mathrm{CH}_{3}, 6 \mathrm{H}\right)$.

Compound 6b, ${ }^{1} \mathrm{H}$ NMR $\left(400 \mathrm{MHz}, \mathrm{CDCl}_{3}\right): \delta=7.32(-\mathrm{CHCHC}-, 1 \mathrm{H}), 6.67(-\mathrm{CCHCH}-, 1 \mathrm{H}), 6.52$ $(-\mathrm{CC} H \mathrm{C}-, 1 \mathrm{H}), 6.20(-\mathrm{CCHCO}-, 1 \mathrm{H}), 5.75(\beta-\mathrm{CD}, \mathrm{OH}, 2 \mathrm{H}), 4.85\left(-\mathrm{CH}_{2} \mathrm{OOC}\right), 4.68(\beta-\mathrm{CD}, \mathrm{CH}$, $1 \mathrm{H}), 4.42\left(-\mathrm{CH}_{2} \mathrm{CONH}-, 2 \mathrm{H}\right), 3.80-2.80\left(\mathrm{PEG},-\mathrm{OCH}_{2} \mathrm{CH}_{2} \mathrm{O}-; \beta-\mathrm{CD}, \mathrm{C}_{2} \mathrm{H}-\mathrm{C}_{6} \mathrm{H} ;-\mathrm{CH}_{2} \mathrm{CH}_{3}\right.$; $\left.-\mathrm{NHCH}_{2} \mathrm{CH}_{2} \mathrm{SH}\right), 1.12\left(\mathrm{CH}_{3}, 6 \mathrm{H}\right)$. 
Preparation of Au nanorods (AuNRs)

AuNRs were prepared according to previous study.[33] The seed-mediated growth method was employed to synthesize AuNRs. $3.7 \mathrm{~mL} \mathrm{CTAB}(0.1 \mathrm{M})$ were mixed with $150 \mu \mathrm{L}$ of $\mathrm{HAuCl}_{4}(0.01$ M) and the volume was adjusted to $4.7 \mathrm{~mL}$ by adding distilled water. $0.3 \mathrm{~mL}$ of ice-cold $\mathrm{NaBH}_{4}$ aqueous solution $(0.01 \mathrm{M})$ was added to the mixture. CTAB capped Au seeds were formed immediately and used within 2-5 h. The growth solution for AuNRs consisted of a mixture of 300 mL CTAB $(0.1 \mathrm{M}), 16 \mathrm{~mL} \mathrm{HAuCl}_{4}(0.01 \mathrm{M}), 3 \mathrm{~mL} \mathrm{AgNO} 3(0.01 \mathrm{M}), 6 \mathrm{~mL} \mathrm{H}_{2} \mathrm{SO}_{4}(0.5 \mathrm{M})$, and $2.4 \mathrm{~mL}$ ascorbic acid $(0.1 \mathrm{M})$. The growth was initiated by adding $1.4 \mathrm{~mL}$ of seeds and stopped after $12 \mathrm{~h}$ by centrifuging twice at $12000 \times g$ for $10 \mathrm{~min}$. The as-synthesized AuNRs were further washed for another four times. The size and shape of the AuNRs were characterized by TEM. A TEM image (Figure S1) showed that the gold nanorodshad an aspect ratio of 3.2 with a mean length of $41.7 \pm 2.8 \mathrm{~nm}$ and width of $13.2 \pm 0.9 \mathrm{~nm}$.The UV-Vis absorbance of the naked AuNRs was approximately $747 \mathrm{~nm}$ (Figure S2).

Preparation of compound 7

The AuNRs was dispersed in $170 \mathrm{~mL}$ deionized water under ultrasound. The solution of compound $6 \mathrm{a}(0.7 \mathrm{~g})$ or compound $6 \mathrm{~b}(0.6 \mathrm{~g})$ dissolved in $5.6 \mathrm{~mL}$ DMF was added dropwise. After stirred for $24 \mathrm{~h}$, the mixture was centrifuged at $12000 \times \mathrm{g}$ for $10 \mathrm{~min}$. The product was dialyzed in a dialysis tubing (Spectra/Por MWCO = 1000) and freeze-dried to obtain compound 7a (RGD-PEG- $\beta$-CD-(AuNRs)-CM) or compound 7b (PEG- $\beta$-CD-(AuNRs)-CM).

Preparation of compound 8

$\mathrm{Au}$ nanoparticles were prepared according previous studies.[34] $2 \mathrm{~mL}$ of $\mathrm{HAuCl}_{4}$ solution $(0.01 \mathrm{M})$ was dissolved in $30 \mathrm{~mL}$ of deionized water. The solution of compound $6 \mathrm{a}(235 \mathrm{mg})$ or compound 6b (200 mg) dissolved in $20 \mathrm{~mL}$ deionized water was added dropwise for $4 \mathrm{~h}, 10 \mathrm{~mL}$ of $\mathrm{NaBH}_{4}$ solution $(0.02 \mathrm{M})$ was added and stirred for $8 \mathrm{~h}$. The mixture was centrifuged at $12000 \times g$ for 10 $\min$. The product was dialyzed in a dialysis tubing (Spectra/Por MWCO=1000) and freeze-dried to obtain compound $8 \mathrm{a}$ (RGD-PEG- $\beta$-CD-(AuNPs)-CM or compound $8 \mathrm{~b}$ (PEG- $\beta$-CD-(AuNPs)-CM).

Preparation of drug loaded nanoparticles

The amphiphiles and DOX were dissolved in DMSO with vigorous stirring for $2.0 \mathrm{~h}$. The solution was dropped into $10 \mathrm{~mL}$ of deionized water under vigorous stirring overnight. Four kinds of amphiphiles were involved in preparation of drug loaded nanoparticles.

The RGD-PEG- $\beta$-CD-(-AuNRs)-CM (50 mg), PEG- $\beta$-CD-(-AuNRs)-CM (150 mg), and DOX (86 $\mathrm{mg}$ ) were dissolved in $30.0 \mathrm{~mL}$ of DMSO with stirring for $2.0 \mathrm{~h}$. The solution was dropped into $500 \mathrm{~mL}$ of deionized water under vigorous stirring overnight.

The RGD-PEG- $\beta$-CD-(-AuNPs)-CM (21 mg), PEG- $\beta$-CD-(-AuNPs)-CM (63 mg), and DOX (36 $\mathrm{mg}$ ) were dissolved in $10.0 \mathrm{~mL}$ of DMSO with stirring for $2.0 \mathrm{~h}$. The solution was dropped into $200 \mathrm{~mL}$ of deionized water under vigorous stirring overnight.

The RGD-PEG- $\beta$-CD-CM (20 mg), PEG- $\beta$-CD-CM (40 mg), and DOX (34.5 mg) were dissolved in $10.0 \mathrm{~mL}$ of DMSO with stirring for $2.0 \mathrm{~h}$. The solution was dropped into $200 \mathrm{~mL}$ of deionized 
water under vigorous stirring overnight.

The mPEG- $\beta$-CD-CM $(80 \mathrm{mg})$ and DOX $(34.5 \mathrm{mg})$ were dissolved in $10.0 \mathrm{~mL}$ of DMSO with stirring for $2.0 \mathrm{~h}$. The solution was dropped into $200 \mathrm{~mL}$ of deionized water under vigorous stirring overnight.

All the mixtures were dialyzed against deionized water at $4{ }^{\circ} \mathrm{C}$ for $12 \mathrm{~h}$ in a dialysis tubing (Spectra/Por, MWCO=2000). The solution was removed from the dialysis tubing, centrifugated and lyophilized. The content of DOX was determined by UV-Vis spectra $(\lambda \max =505 \mathrm{~nm})$ in DMSO using calibration curve obtained from DOX/DMSO solutions with different DOX concentrations $\left(A=0.0219 \mathrm{C}-0.0098, \mathrm{R}^{2}=0.9998, \mathrm{C} \mu \mathrm{g} / \mathrm{mL}\right.$ ). The whole procedure was in dark. The drug loading content (DLC) and encapsulation efficiency (EE) were calculated from the following formulae:[35]

DLC $(\%)=($ weight of drug in micelle/weight of drug loaded micelle $) \times 100 \%$

$\mathrm{EE}(\%)=($ weight of drug in micelle/weight of drug in feeding $) \times 100 \%$

In vitro release profiles

DOX-loaded nanoparticles were dispersed in PBS $(1 \mathrm{~mL}$, ionic strength $=0.01 \mathrm{M}, \mathrm{pH}=7.4)$. All the experiments were employed under sink conditions in order to ensure the good solubility of DOX. The mixture was put in dialysis tubings (Spectra/Por MWCO $=1000)$. The tubings were immersed in vials containing $25 \mathrm{~mL}$ of phosphate buffered saline (PBS) solution, and put in a shaking bed at $37^{\circ} \mathrm{C} .1 \mathrm{~mL}$ of PBS solution was taken out and the same volume of PBS was added to the vials at prescribed time intervals. At interval time of 90, 120, 210 and 300 minutes, the solution were exposed to NIR ( $808 \mathrm{~nm}, 400 \mathrm{~mW}$ ) for $5 \mathrm{~min}$. The released DOX was determined by a fluorescence detector with excitation wavelength at $485 \mathrm{~nm}$ and emission wavelength at 550 $\mathrm{nm}$. The release experiments were conducted in triplicate, and the results were demonstrated as mean \pm SD.

\section{Cytotoxicity test}

The NIH 3T3 fibroblasts and 4T1 breast cancer cells $\left(5 \times 10^{3}\right.$ cells $\left./ \mathrm{mL}\right)$ were harvested and seeded in 96-well plates with $100 \mu \mathrm{L}$ mediums for $24 \mathrm{~h}$ incubation before the tests. Blank nanoparticles in culture mediums were added to the medium-removed 96-well plates with different concentrations and incubated for $48 \mathrm{~h}$. The culture medium was removed and the wells were washed with PBS $(\mathrm{pH}=7.4)$. CCK-8 in DMEM (10\%) was added to each well. After the cells were incubated for additional $4 \mathrm{~h}$, the cell viability was determined by measuring the absorption at $450 \mathrm{~nm}$ using a microplate reader (Thermo Scientific MK3).

In vitro anticancer activity

The 4T1 breast cancer cells $\left(5 \times 10^{3}\right.$ cells $\left./ \mathrm{mL}\right)$ were harvested and seeded in 96 -well plates with $100 \mu \mathrm{L}$ medium for $24 \mathrm{~h}$ incubation before the tests. $4 \mathrm{~T} 1$ breast cancer cells were incubated with DOX-loaded micelles (a certain concentration of DOX $0.4 \mu \mathrm{g} / \mathrm{mL}$ ) for $5 \mathrm{~h}$ and exposed to NIR laser irradiation with a wavelength of $808 \mathrm{~nm}$ laser (400 $\mathrm{mW}$ ) for $0,1,2$, and $3 \mathrm{~min}$, respectively. After laser irradiation, the cells were incubated with media for $48 \mathrm{~h}$. The culture medium was removed and the wells were washed with PBS (pH=7.4). CCK-8 dilution in DMEM (10\%) was 
added to each well. After the cells were incubated for additional $4 \mathrm{~h}$, the cell viability was determined by measuring the absorption at $450 \mathrm{~nm}$ using a microplate reader (Thermo Scientific MK3).

Cellular uptake

$4 \mathrm{~T} 1$ breast cancer cells were seeded on (diameter $=35 \mathrm{~mm}$ ) glass dishes with a cell density of $1 \times 10^{5} \mathrm{~mL}^{-1}$. After incubated for $24 \mathrm{~h}$, the cancer cells were treated with DOX-loaded nanoparticles (DOX concentration was $10 \mu \mathrm{g} / \mathrm{mL}$ ) at $37{ }^{\circ} \mathrm{C}$ for 2,5 and $12 \mathrm{~h}$. The medium of all samples was removed and the dishes were rinsed with PBS $(\mathrm{pH}=7.4)$. The cells were observed with confocal laser scanning microscopy (Leica TCP SP5). DOX was excited at $480 \mathrm{~nm}$ with the emission at 590 $\mathrm{nm}$.

For flowcytometry study, 4T1 breast cancer cells were seeded on 6-well plates with a density of $2 \times 10^{5}$ cells/well and cultured for $24 \mathrm{~h}$. $4 \mathrm{~T} 1$ breast cancer cells were incubated with DOX-loaded micelles (DOX concentration was $10 \mathrm{ug} / \mathrm{mL}$ ) at $37{ }^{\circ} \mathrm{C}$ for 2,5 and $12 \mathrm{~h}$. The cells were resuspended in PBS after centrifugation (1000 rpm/min, $5 \mathrm{~min}$ ) and measured for the fluorescence intensity (excitation at480 $\mathrm{nm}$ and emission at $590 \mathrm{~nm}$ ) [29] on a BD FACS Caliburflowcytometer (Beckton Dickinson).

In vivo anticancer activity

All animal experiments were performed in line with animal experiments ethical committee for care and use of research animals. Male BALB/c mice (body weight: 18-22 g) were purchased from West China Animal Culture Center of Sichuan University. $5 \times 10^{5} 4 \mathrm{~T} 1$ breast cancer cells were injected into right flank subcutaneously of BALB/c mice. After the inoculated tumor volume reached $100-200 \mathrm{~mm}^{3}$, the mice were randomly divided into 10 groups and treated with saline, saline plus $808 \mathrm{~nm}$ laser $(800 \mathrm{~mW})$ irradiation, DOX/RGD-PEG- $\beta$-CD-(AuNR $)_{\mathrm{S}}$-CM nanoparticles, DOX/RGD-PEG- $\beta$-CD-(AuNR $)$-CM nanoparticles plus $808 \mathrm{~nm}$ laser (400 mW or $800 \mathrm{~mW}$ ) irradiation, DOX/RGD-PEG- $\beta$-CD-(AuNP $)$-CM nanoparticles plus $808 \mathrm{~nm}$ laser (800 $\mathrm{mW}$ ) irradiation, DOX/RGD-PEG- $\beta$-CD-CM nanoparticles plus $808 \mathrm{~nm}$ laser (800 mW) irradiation, DOX/mPEG- $\beta$-CD-CM nanoparticles plus $808 \mathrm{~nm}$ laser $(800 \mathrm{~mW})$ irradiation, and $\mathrm{DOX} \cdot \mathrm{HCl}$, respectively. These mice were injected intravenously via the tail vein with DOX dose of $5 \mathrm{mg} / \mathrm{kg}$ body weight. All samples were injected for four times at 3-day interval, and the tumor regions were exposed to the laser irradiation for $5 \mathrm{~min}$ after the injection. The body weights of mice and the tumor volume were measured, the behaviors of mice were determined by the animal healthcare technicians. Tumor volumes were calculated using the formula $V=(a x(b x b)) / 2$, with a (the largest diameter) and $\mathrm{b}$ (the smallest diameter). After 30 days, the mice in all groups were randomly picked out and sacrificed. Major organs from each mouse were taken out, fixed in $4 \%$ formaldehyde, processed routinely into paraffin, sectioned, stained with hematoxylin and eosin (H\&E) and examined by a digital microscope. Examined tissues included tumor, heart, liver, spleen, lung and kidney.

Serum biochemistry

Tumor-bearing mice were injected with DOX-loaded nanoparticles $(5 \mathrm{mg} / \mathrm{kg})$. Saline was injected 
healthy male mice as control. Mice were sacrificed to collect the blood forserum biochemistry assay at 15 th day post-injection. The serumchemistry data were measured by Chengdu Lilai Biotechnology Co., Ltd.

Statistical analysis

Data were analyzed using Prism 4 (Graph Pad Prism 5 Software, San Diego, CA) and expressed as mean \pm standard $(\mathrm{SD})$ deviation. Statistical significance $(\mathrm{P}<0.05)$ was evaluated using student t-test.

\section{Results and discussion}

Table 1. The summarized parameters of drug loaded nanoparticles (NPs). Data represent the mean \pm standard deviation $(\mathrm{n}=3)$.

\begin{tabular}{|c|c|c|c|c|c|c|}
\hline \multirow{2}{*}{ Amphiphile } & \multicolumn{4}{|c|}{ Mean diameter of NPs (nm) } & \multirow{2}{*}{$\operatorname{DLC}(\%)$} & \multirow{2}{*}{$\mathrm{EE}(\%)$} \\
\hline & Blank & PDI & Drug loaded & PDI & & \\
\hline mPEG- $\beta$-CD-CM & $150.9 \pm 2.5$ & 0.341 & $160.9 \pm 1.5$ & 0.218 & $22.2 \pm 0.2$ & $66.3 \pm 0.5$ \\
\hline RGD-PEG- $\beta$-CD-CM & $124.9 \pm 1.8$ & 0.240 & $132.3 \pm 1.3$ & 0.275 & $12.0 \pm 0.1$ & $32.0 \pm 0.4$ \\
\hline RGD-PEG- $\beta$-CD-(-AuNRs)-CM & $239.5 \pm 3.8$ & 0.530 & $245.6 \pm 2.1$ & 0.450 & $28.5 \pm 0.2$ & $93.1 \pm 0.9$ \\
\hline RGD-PEG- $\beta-C D-(-A u N P s)-C M$ & $255.6 \pm 0.4$ & 0.293 & $270.6 \pm 1.3$ & 0.225 & $17.5 \pm 0.3$ & $49.6 \pm 0.9$ \\
\hline
\end{tabular}

DLC: Drug loading content.

EE: Encapsulation efficiency
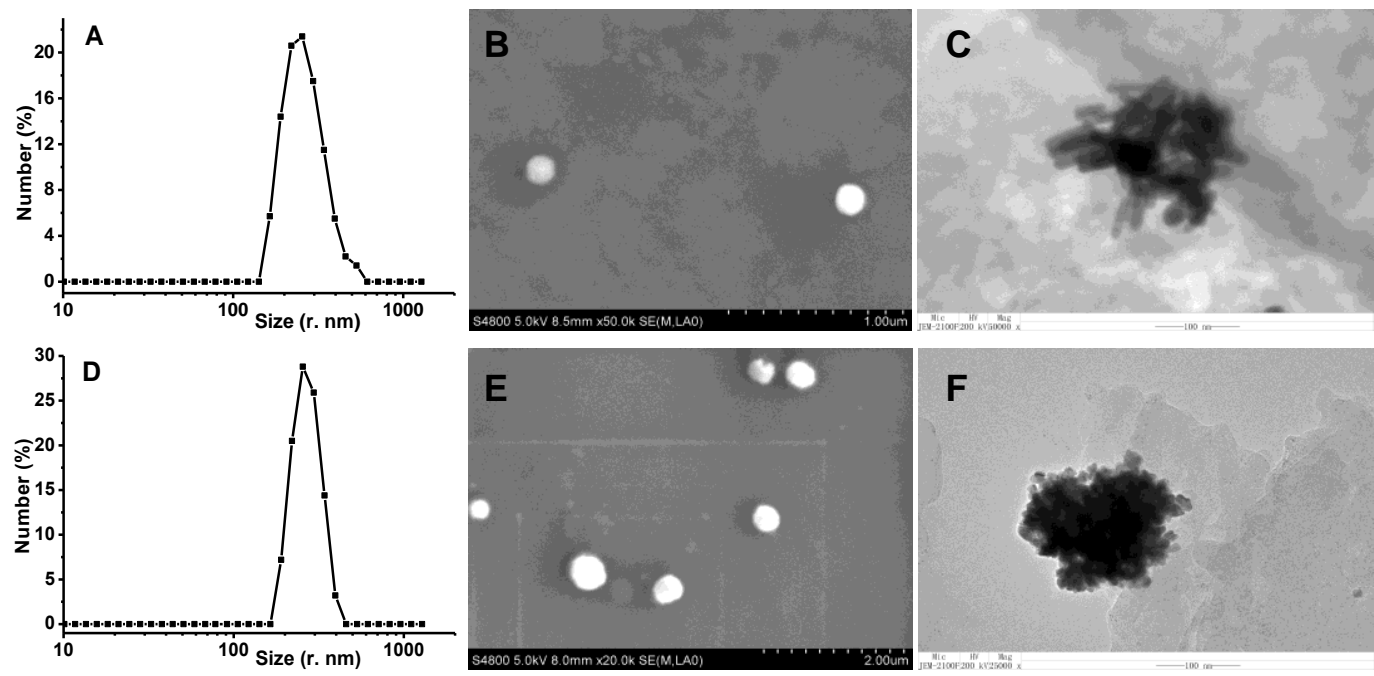

Figure 2. The size (DLS) and morphology (SEM and TEM images) of drug loaded RGD-PEG- $\beta$-CD-(AuNRs)-CM (A， B, C) and RGD-PEG- $\beta$-CD-(AuNPs)-CM (D, E, F) nanoparticles.

Four amphiphies of mPEG- $\beta$-CD-CM, RGD-PEG- $\beta$-CD-CM, RGD-PEG- $\beta$-CD-(AuNRs)-CM and RGD-PEG- $\beta$-CD-(AuNPs)-CM were synthesized as carriers (Scheme 1), the amphiphiles 
self-assembled into nanoparticles to load DOX. The size distributions of the four blank and drug loaded nanoparticles were measured by DLS (Table 1, Figure 2A and 2B). The mean diameters of the four drug loaded nanoparticles were 160.9, 132.3, 245.6, and $270.6 \mathrm{~nm}$, which were bigger than those of corresponding blank nanoparticles due to drug encapsulation. Both blank and drug loaded nanoparticles exhibited good size distribution of monodisperse in DLS spectra. The SEM (Figure 2B and 2E) and TEM (Figure 2C and $2 \mathrm{~F}$ ) images of two blank and drug loaded hybrid nanoparticles of RGD-PEG- $\beta$-CD-(AuNRs)-CM and RGD-PEG- $\beta$-CD-(AuNPs)-CM revealed that the sizes of the nanoparticles were around $250 \mathrm{~nm}$.

The drug loading content (DLC) and encapsulation efficiency (EE) of the nanoparticles were summarized in Table 1. The DLC and EE of the mPEG- $\beta$-CD-CM nanoparticles were $22.2 \%$ and $66.3 \%$, respectively. The DLC (12.0\%) and EE (32.0\%) decreased when the mPEG- $\beta$-CD-CM nanoparticles was modified by RGD, probably due to that the cycle structure of RGD prevented the interaction of DOX and DEACM. When RGD-PEG- $\beta$-CD-CM conjugate was further modified with AuNRs, the large cavity in nanoparticles caused by irregular arrangement of AuNRs improved the drug loading efficiency greatly. The DLC and EE of RGD-PEG- $\beta$-CD-(AuNRs)-CM nanoparticles were $28.5 \%$ and $93.1 \%$. Comparing to AuNRs modified nanoparticles, the DLC and EE of AuNPs modified mPEG- $\beta$-CD-CM nanoparticles were much lower.

In the four nanoparticles, both $\beta$-CDs and $\pi$-conjugated coumarin derivative moieties gave great contribution to the improvement of drug loading efficiency. When DOX was encapsulated in the mPEG- $\beta$-CD-CM nanoparticles, the $\pi-\pi$ stacking interaction between drugs and nanoparticles were formed due to the $\pi$ conjugated moieties in both DOX and mPEG- $\beta$-CD-CM nanoparticles, it was characterized by fluorescence spectra. The red shift of $10 \mathrm{~nm}$ from 437 to $447 \mathrm{~nm}$ was observed in the fluorescence spectra when the concentration of mPEG- $\beta$-CD-CM was increased from 8 to $250 \mu \mathrm{g} / \mathrm{mL}$. It implied that the $\pi-\pi$ stacking interaction within mPEG- $\beta$-CD-CM nanoparticles was formed as the red shift was the characteristic of $\pi-\pi$ stacking (Figure S3). [36]
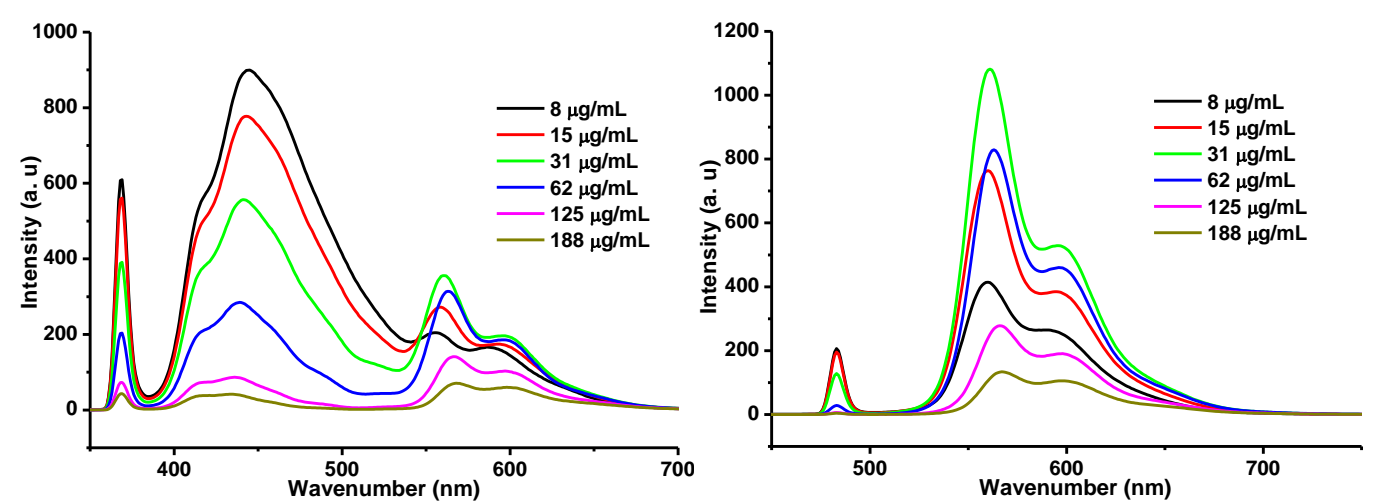

Figure 3. The fluorescence spectra of DOX with different concentrations in the solution of mPEG- $\beta$-CD-CM conjugate $(250 \mu \mathrm{g} / \mathrm{mL}$ in DMSO), A: excitation at $365 \mathrm{~nm}$ for the emission of fluorescence in coumarin derivative moieties; B: excitation at $480 \mathrm{~nm}$ for the emission of DOX.

The fluorescence spectra of DOX in the solution of mPEG- $\beta$-CD-CM conjugate with different 
concentrations were measured. There were two chromophores of coumarin derivative and DOX existed in the drug loaded nanoparticles, thus, two excitation wavelengths were carried out at 365 and $480 \mathrm{~nm}$, the excitation at $365 \mathrm{~nm}$ was to collect the fluorescence of coumarin derivative moieties at $425 \mathrm{~nm}$ and the excitation at 480 was to collect the fluorescence of DOX at $550 \mathrm{~nm}$. (Figure 3). With the excitation at $365 \mathrm{~nm}$, the intensity of $\mathrm{mPEG}-\beta-\mathrm{CD}-\mathrm{CM}$ fluorescence $(E m=425 \mathrm{~nm})$ was weakened with increasing the concentration of DOX. The quenching of mPEG- $\beta$-CD-CM fluorescence was observed. When excited at $480 \mathrm{~nm}$, the increase of DOX fluorescence was attributed to the increase of DOX concentration from 8 to $31 \mu \mathrm{g} / \mathrm{mL}$. The fluorescence quenching occurred once the concentration of DOX was higher than $62 \mu \mathrm{g} / \mathrm{mL}$. Both the fluorescence quenching of coumarin derivative and DOX in Figure 3 demonstrated the formation of $\pi-\pi$ stacking interaction between DOX and mPEG- $\beta$-CD-CM conjugate. To further explore the $\pi-\pi$ stacking interaction within the DOX-loaded mPEG- $\beta$-CD-CM nanoparticles, the fluorescence spectra of drug loaded nanoparticles were tested in PBS (Figure S4). The intensity of DOX fluorescence increased with increasing the concentration of DOX-loaded nanoparticles to $125 \mu \mathrm{g} / \mathrm{mL}$. The quenching occurred when the concentration was higher than $250 \mu \mathrm{g} / \mathrm{mL}$,
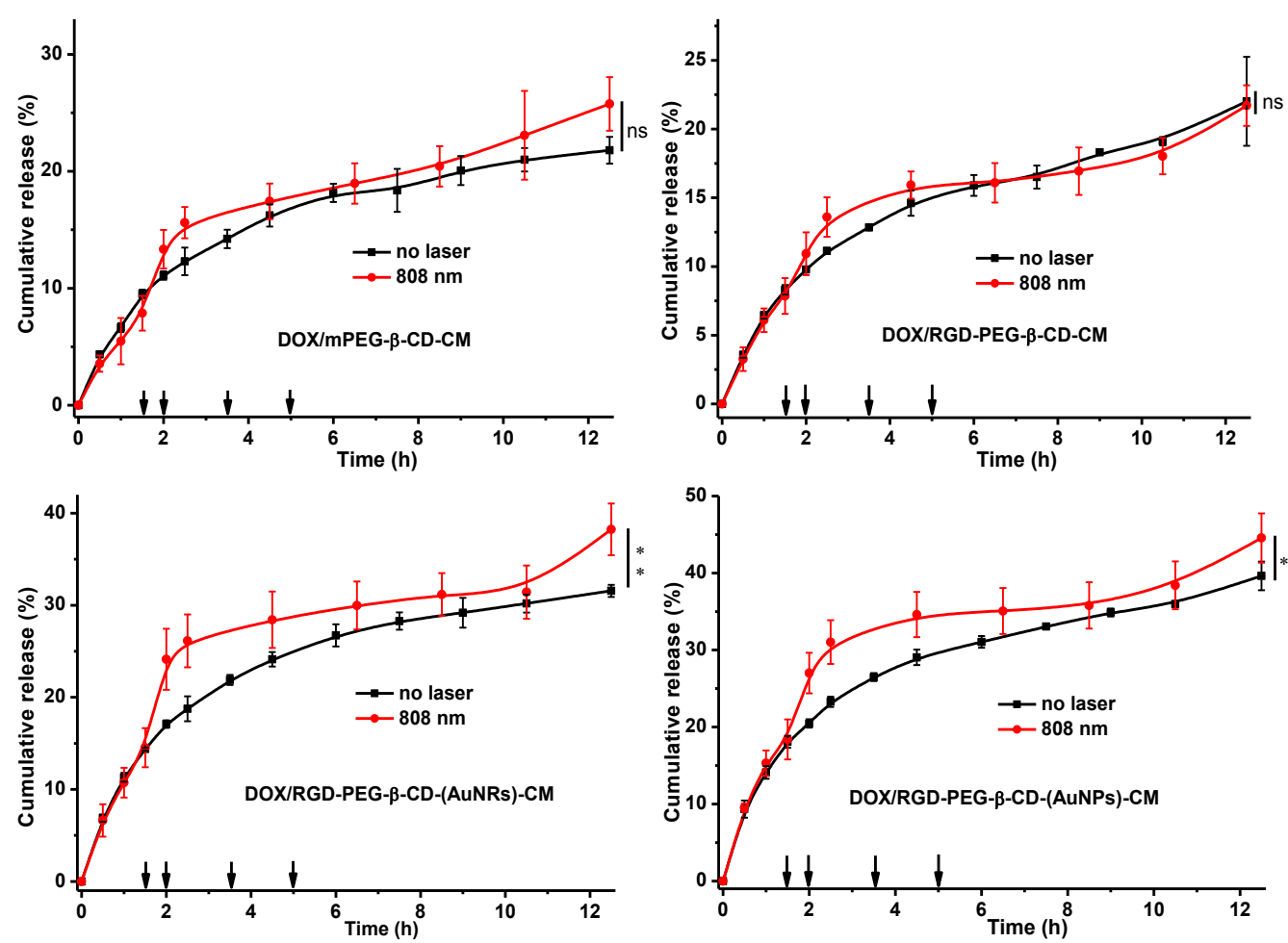

Figure 4. The release profiles of DOX-loaded nanoparticles in PBS (pH 7.4). At time intervals of 90, 120, 210 and 300 minutes, the solution were exposed to NIR laser $(808 \mathrm{~nm}, 400 \mathrm{~mW})$ for 5 min. Means \pm SD $(n=3)$. A: DOX/mPEG- $\beta$-CD-CM;B: DOX/RGD-PEG- $\beta$-CD-CM;C: DOX/RGD-PEG- $\beta$-CD-(AuNRs)-CM; D：DOX/RGD-PEG- $\beta$-CD-(AuNPs)-CM) (ns meant no significant difference, $* \mathrm{P}<0.05, \mathrm{P}=0.0312 ; * * \mathrm{P}<0.01, \mathrm{P}=0.0018)$.

The photosensitivity of the nanoparticles under NIR $(808 \mathrm{~nm})$ irradiation was tested. As the 
chromophore of coumarin derivatives in the hybrid nanoparticles emitted fluoresce upon UV (365 $\mathrm{nm}$ ) excitation, the coumarin groups would be suffered from self-quenching and lowered fluorescence emission when confined to the nanoparticles core. After photosolvolysis and released into water, the fluorescence intensity of the solution containing coumarin moieties would be enhanced dramatically. Therefore, monitoring the photoinduced release of coumarin groups could be used to detect the nanoparticles disruption and the release of therapeutics.[28, 37, 38] The solutions of nanoparticles were exposed to NIR laser with $808 \mathrm{~nm}$ wavelength at the time point of 90, 120, 210 and 300 minutes. Two nanoparticles of mPEG- $\beta$-CD-CM and RGD-PEG- $\beta$-CD-(AuNRs)-CM were used to investigate the effect of NIR on the photosolvolysis of DEACM moiety (Figure S5). The fluorescence emission spectra of the nanoparticles solution was recorded upon the excitation of coumarin side groups $(E x=365 \mathrm{~nm})$. Before NIR irradiation, the emission of coumarin at $425 \mathrm{~nm}$ was low. The fluorescence intensity increased greatly after 5 min NIR irradiation for the first time at 90 minutes. The DEACM moiety was photocleaved from the nanoparticles to result in the enhancement of fluorescence intensity. With the comparison of the fluorescence spectra of mPEG- $\beta$-CD-CM and RGD-PEG- $\beta$-CD-(AuNRs)-CM nanoparticles, it was clear that $\mathrm{Au}$ nanorods could accelerate the photosolvolysis of DEACM moiety as the fluorescence of coumarin derivative in the solution of RGD-PEG- $\beta$-CD-(AuNRs)-CM nanoparticles was much stronger than that of mPEG- $\beta$-CD-CM. The cleavage of the ester bond in 7-(diethylamino)-4-(hydroxymethyl)-2H-chromen-2-one moieties destroyed the architecture of nanoparticles and accelerated the release of DOX (Figure 4).

The drug release in the medium with $\mathrm{pH}=7.4$ was slower than that in the medium with $\mathrm{pH}=5.5$. In addition, there was little difference between the samples with and without NIR irradiation in the drug release when the $\mathrm{pH}$ value of medium was 5.5 (Figure S6). In the medium with $\mathrm{pH}=5.5$, the protonation of DOX accelerated drug release. The protonation effect on drug release was more serious than that of NIR effect, which covered the NIR effect on drug release.
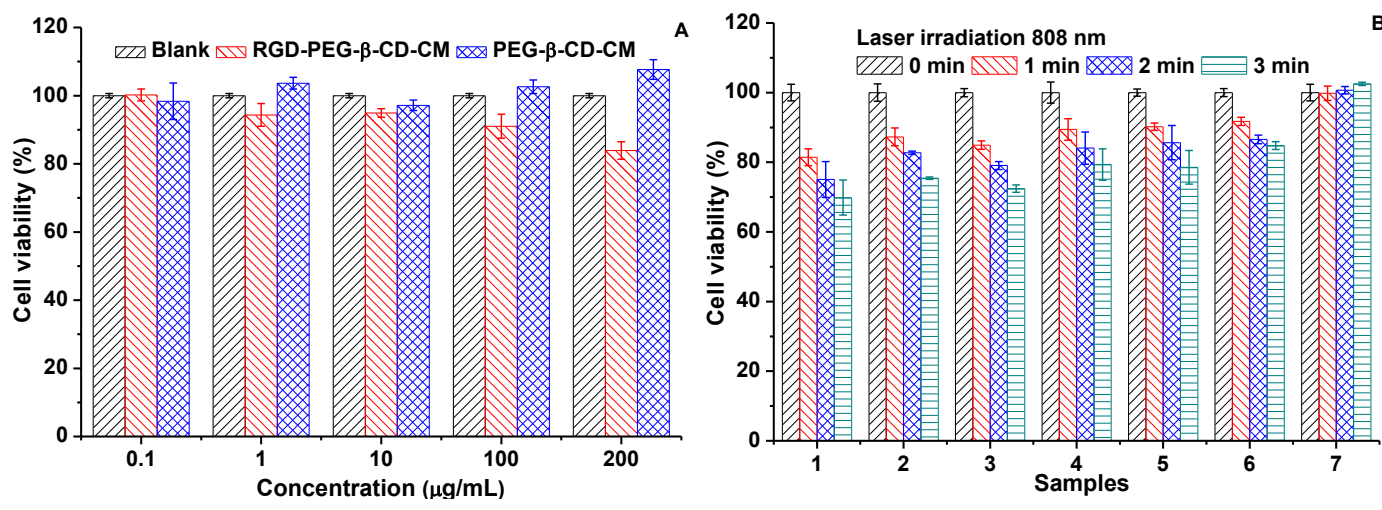

Figure 5. Cytotoxicity of blank and DOX-loaded nanoparticles to NIH 3T3 fibroblasts and 4T1 breast cancer cells, A: cell viability of NIH $3 \mathrm{~T} 3$ fibroblasts cells incubated with different concentrations of blank nanoparticles for $48 \mathrm{~h}$; B: cell viability of $4 \mathrm{~T} 1$ breast cancer cells incubated with DOX-loaded nanoparticles (DOX concentration of $0.4 \mu \mathrm{g} / \mathrm{mL}$ ) and exposed to 808 
$\mathrm{nm}$ NIR $(400 \mathrm{~mW})$ for $0, \quad 1,2$, and 3 minutes. Samples 1 to 7 were DOX/RGD-PEG- $\beta-C D-\left(\mathrm{AuNR}_{\mathrm{S}}\right)-\mathrm{CM}$,

DOX/RGD-PEG- $\beta-C D-\left(\right.$ AuNP $\left._{S}\right)-C M$, DOX/RGD-PEG- $\beta$-CD-CM, DOX/mPEG- $\beta$-CD-CM, AuNRs, AuNPs, and control.

The cytotoxicity of blank RGD-PEG- $\beta-C D-C M$ and mPEG- $\beta-C D-C M$ nanopartilces was evaluated with NIH/3T3 fibroblasts (Figure 5A). The cell viability of NIH/3T3 fibroblasts were beyond $80 \%$ even the concentration of the nanoparticles was as high as $200 \mu \mathrm{g} / \mathrm{mL}$. The result indicated that the nanoparticles were non-toxic to NIH/3T3 fibroblasts cells.[39]

In order to evaluate the in vitro anticancer activity of DOX-loaded nanoparticles, seven samples were selected as shown in Figure 5B. The effect of NIR laser $(808 \mathrm{~nm}, 400 \mathrm{~mW})$ on the blank cells (sample 7) was also evaluated at the same time. The cell viabilities were higher than $90 \%$ when the cells were exposed to NIR laser for $0,1,2$ and $3 \mathrm{~min}$. There was no significant difference between the samples exposed to NIR laser with different time. Therefore, the effect of NIR laser irradiation on cell viability could be ignored. The cell viability of DOX-loaded nanoparticles without irradiation was used as control to evaluate the cytotoxicity of DOX-loaded nanoparticles with NIR laser irradiation. When the samples were exposed to NIR, the difference in cytotoxicity was obvious with the increase of irradiation time. To mPEG- $\beta$-CD-CM (sample 4), the best inhibition effect appeared in the sample with 3 min NIR irradiation due to the serious photosolvolysis of DEACM esters to accelerate the release of DOX.[40] There was significant difference between the groups of 0 to $1 \min (\mathrm{P}<0.001 * * *), 1$ to $2 \min (\mathrm{P}<0.01 * *)$, and 2 to 3 min $(\mathrm{P}<0.01 * *)$.

The RGD-PEG- $\beta$-CD-CM group (sample 3) showed better inhibition effect on cell growth comparing to sample 4 as cRGD moiety exerted its active targeting function. There was significant difference between Sample 3 and 4 with the same laser irradiation time (Sample 3 vs Sample 4, $\mathrm{P}<0.001 * * *$ for $1 \mathrm{~min}$ irradiation, $\mathrm{P}<0.001 * * *$ for 2 min irradiation and $\mathrm{P}<0.001 * * *$ for 3 min irradiation).

Sample 1 (RGD-PEG- $\beta-C D-\left(\right.$ AuNR $\left.\left._{S}\right)-C M\right)$ exhibited the best inhibition effect on cell growth within all the samples. The cytotoxicity originated not only the photosolvolysis of DEACM under NIR irradiation in the presence of $\mathrm{Au}$ nanorods to trigger the fast release of DOX but also the photothermal effect of AuNRs.[41] There was significant difference between sample 1 and sample 5 (Sample 1 vs Sample 5, $\mathrm{P}<0.01 * *$ for $1 \mathrm{~min}$ NIR irradiation, $\mathrm{P}<0.001 * * *$ for $2 \operatorname{minNIR}$ irradiation, $\mathrm{P}<0.001 * * *$ for 3 minNIR irradiation). The significant difference was also found between sample 1 and sample 4 (Sample 1 vs Sample 4, P<0.001 ***for 1 min irradiation, $\mathrm{P}<0.001 * * *$ for 2 minirradiation, $\mathrm{P}<0.001 * * *$ for 3 minirradiation). To sample 1 itself, significant difference existed between the samples with different laser irradiation time, 0 min vs 1 $\min (\mathrm{P}<0.001 * * *), 1 \min \mathrm{vs} 2 \min (\mathrm{P}<0.01 * *), 2 \min$ vs $3 \min (\mathrm{P}<0.01 * *)$.

Simultaneously, significant differences were found between different samples with the same laser irradiation time of $3 \mathrm{~min}$. Sample 1 vs Sample $2(\mathrm{P}<0.05 *)$, Sample 1 vs Sample $3(\mathrm{P}<0.01 * *)$, Sample 1 vs Sample 4 ( $\mathrm{P}<0.001 * * *)$, Sample 1 vs Sample $5(\mathrm{P}<0.001 * * *)$, Sample 1 vs Sample 
$6(\mathrm{P}<0.001 * * *)$, Sample 1 vs Sample $7(\mathrm{P}<0.001 * * *)$, Sample 3 vs Sample $4(\mathrm{P}<0.001 * * *)$, Sample 2 vs Sample $6 \quad(\mathrm{P}<0.001 * * *)$. These results revealed that the NIR-sensitive RGD-PEG- $\beta$-CD-(AuNR $)_{S}-C M$ nanoparticles exhibited the best anticancer activity in vitro with the combination of targeting chemotherapy and phototherma therapy.

Sample 2 (RGD-PEG- $\left.\beta-C D-\left(A_{u N P}\right)-C M\right)$ also possessed the combination of targeting chemotherapy and photothermal therapy, its anticancer activity was as good as Sample 1 as the AuNRs could absorb NIR more efficiently to result in better photosolvolysis and photothermal effect.[42, 43]

In this paper, the concentration of DOX used for in vitro evaluation was $0.4 \mu \mathrm{g} / \mathrm{mL}$, it was a very low concentration. The examples were exposed to the NIR light for 1, 2, and 3 minutes. The difference was clear between the samples with and without NIR irradiation, the cell viability of the sample with NIR irradiation was lower than that of corresponding sample without NIR irradiation, and the longer irradiation time corresponded lower cell viability. The samples with Au nanrods showed lower cell viability comparing to the samples with Au nanoparticles because NIR laser was an approach for clinical cancer treatments [44], and the photothermal effect of Au nanorods was better than that of Au nanoparticles to kill cancer cells effectively.[45]

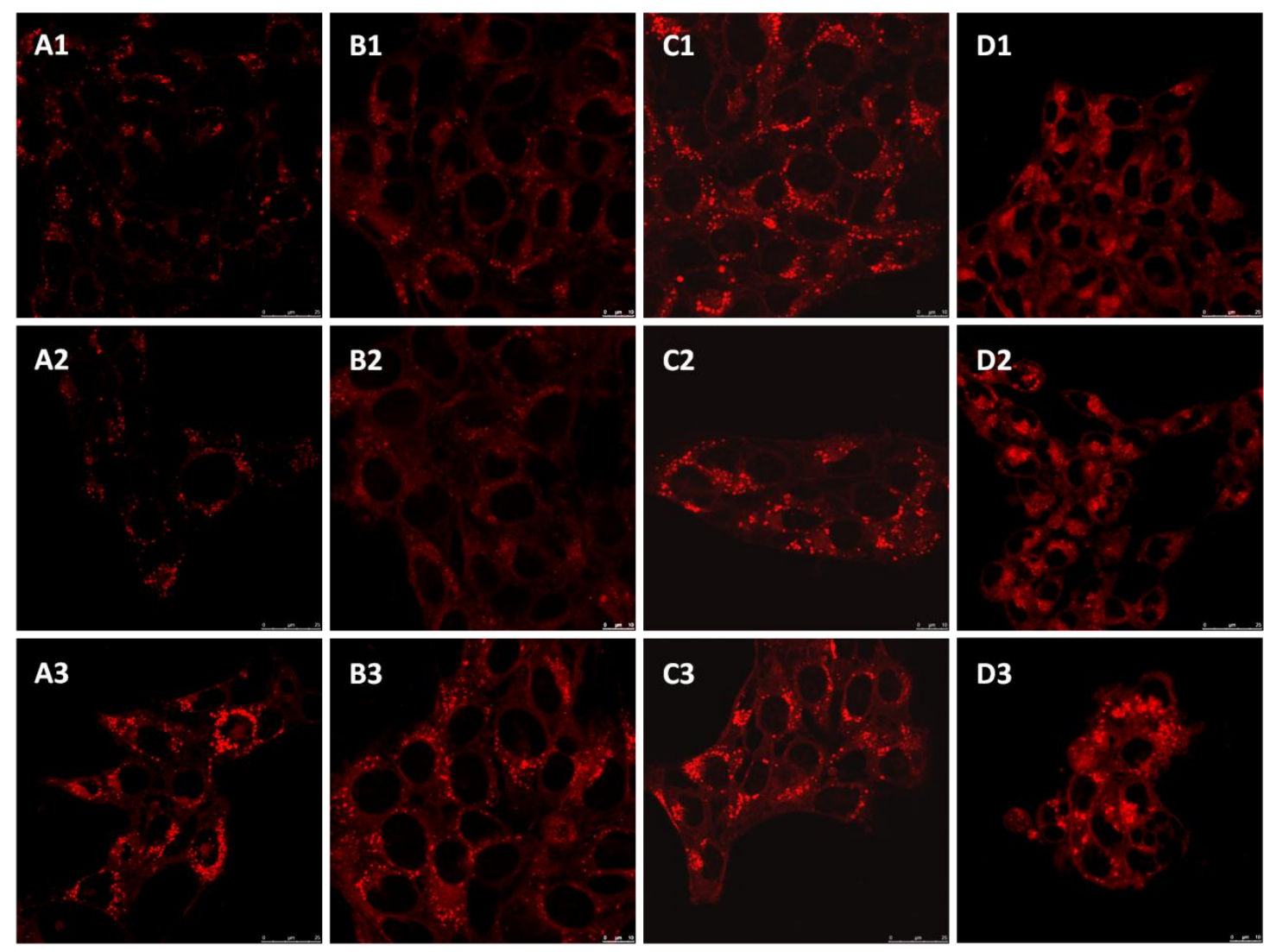



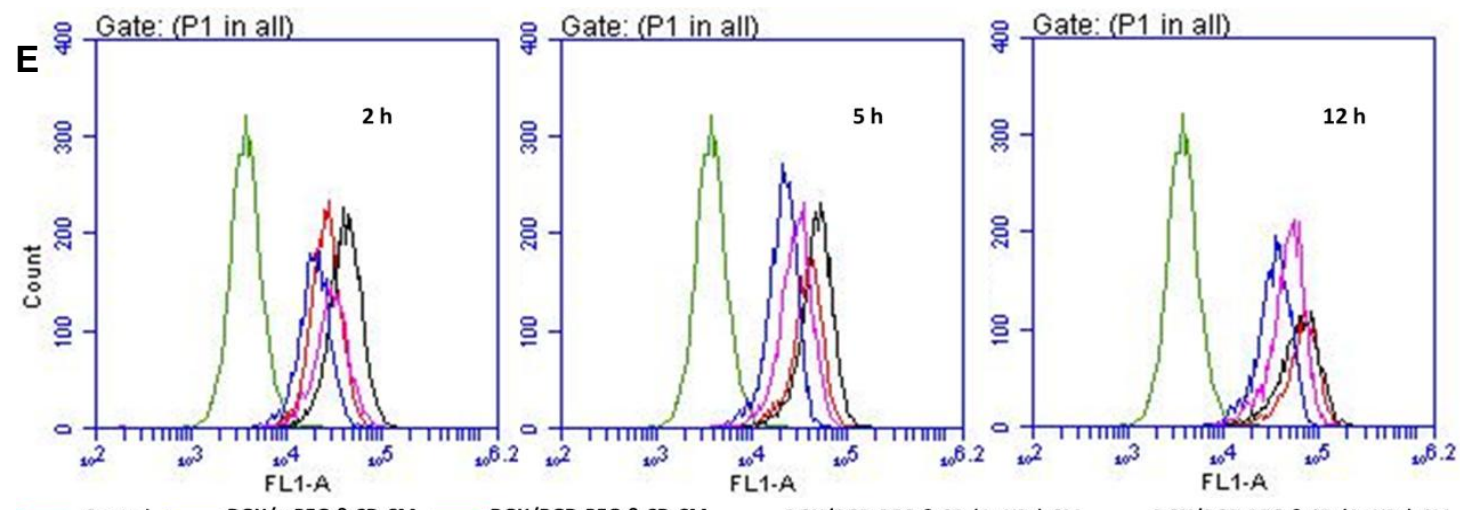

Figure 6. The confocal microscopy images and the flow cytometry results of 4T1 cells treated with DOX-loaded nanoparticles (A) DOX/mPEG- $\beta$-CD-CM; (B) DOX/RGD-PEG- $\beta$-CD-CM; (C) DOX/RGD-PEG- $\beta$-CD-(AuNRs)-CM; (D) DOX/RGD-PEG- $\beta$-CD-(AuNPs)-CM at $37^{\circ} \mathrm{C}$ for $2 \mathrm{~h}$ (A1, B1, C1 and D1), 5h (A2, B2, C2 and D2), and 12h (A3, B3, C3 and D3). The concentration of DOX was $10 \mu \mathrm{g} / \mathrm{mL}$.

Cellular uptake would indicate the internalization capacity of drug loaded nanoparticles to cancer cells. Confocal laser scanning microscopy (CLSM) and flow cytometry were used to characterize the endocytosis of DOX-loaded nanoparticles to $4 \mathrm{~T} 1$ breast cancer cells (Figure 6). The DOX-loaded nanoparticles were incubated with $4 \mathrm{~T} 1$ cells for 2,5 , and $12 \mathrm{~h}$, respectively. The red fluorescence of DOX-loaded nanoparticles was mainly in cytoplasm in the CLSM images, To DOX-loaded mPEG- $\beta$-CD-CM (Figure 6A) and RGD-PEG- $\beta$-CD-CM (Figure 6B) samples, the fluorescence intensity for $12 \mathrm{~h}$ incubation was much stronger than that for $5 \mathrm{~h}$ or $2 \mathrm{~h}$ incubation. It implied that more DOX-loaded nanoparticles were internalized in cells. The cellular uptake was faster in AuNRs or AuNPs modified hybrid nanoparticles, strong red fluorescence was observed even for only $2 \mathrm{~h}$ incubation (Figure 6C and Figure 6D).

The quantitative results of cellular uptake of DOX-loadednanoparticles were tested by flow cytometry (Figure 6E). The fluorescence intensity of cells incubated with DOX/RGD-PEG- $\beta$-CD-(AuNRs)-CM was the highest, and the decreasing sequences were DOX/RGD-PEG- $\beta$-CD-(AuNPs)-CM, DOX/RGD-PEG- $\beta$-CD-CM, and DOX/mPEG- $\beta$-CD-CM. All the cell-associated intensities increased with elongated incubation time. 4T1 cells treated with DOX/RGD-PEG- $\beta$-CD-(AuNRs)-CM nanoparticles showed the highest cellular uptake, which was in agreement with the results of confocal laser scanning microscopy. As cRGD is an efficient receptor for the internalization of nanoparticles to most tumor cells, which has been used to improve the targeting of nanomedicines by selectively binding to $\alpha_{v} \beta_{3} / \alpha_{v} \beta_{5}$ integrins over expressed on cancer cells, thus, the cellular uptake of cRGD modified nanoparticles was higher than that of non-cRGD modified nanoparticles. 

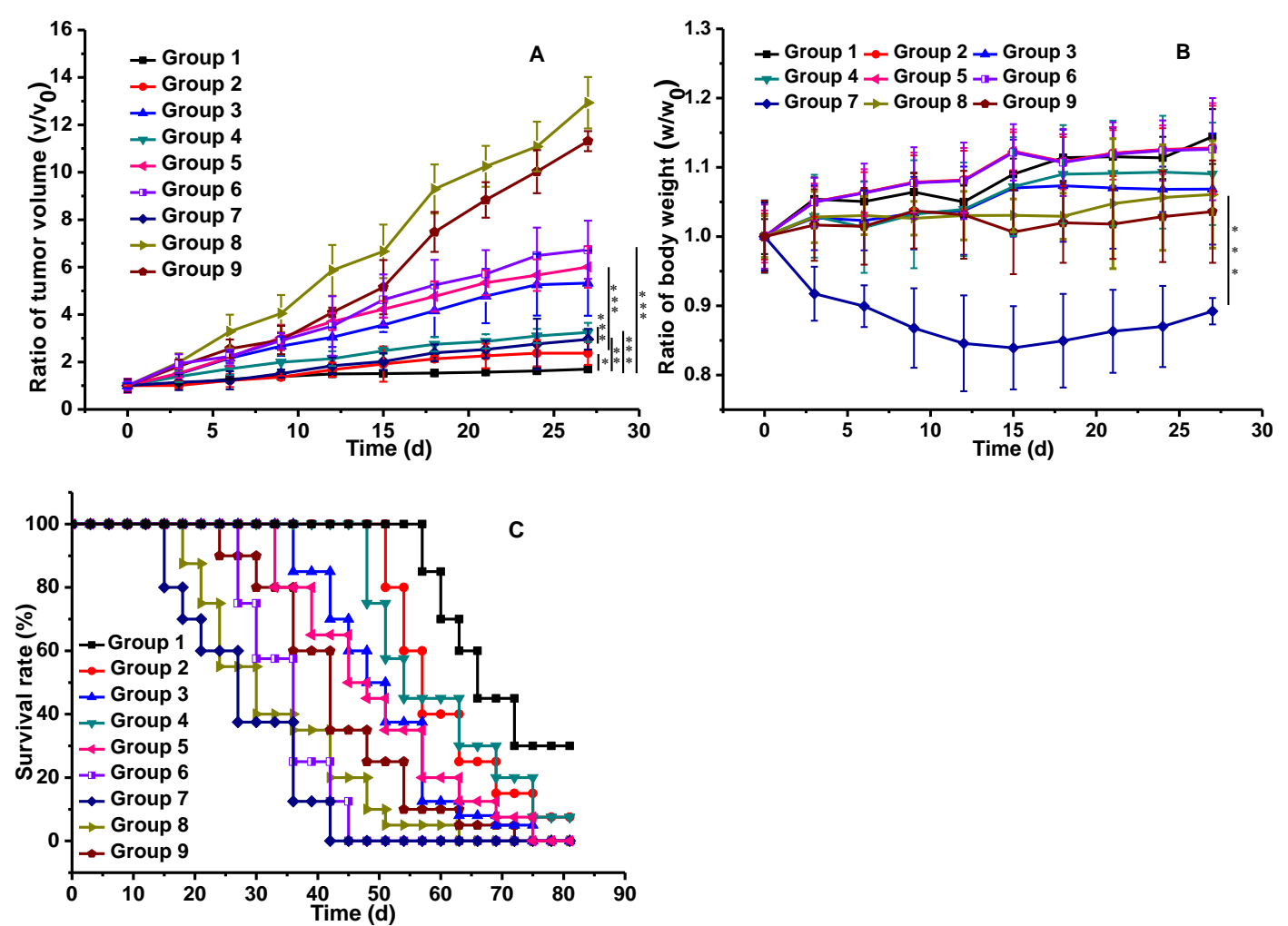

Figure 7. The in vivo anticancer activity of dox-loaded nanoparticles, A: the volumes of tumors; B: body weights; C: survival rates. Group 1: DOX/RGD-PEG- $\beta$-CD-(AuNRs)-CM with NIR irradiation (808 nm, $800 \mathrm{~mW}$ ); Group 2: DOX/RGD-PEG- $\beta$-CD-(AuNRs)-CM with NIR irradiation (808 nm, $400 \mathrm{~mW}$ ); Group 3: DOX/RGD-PEG- $\beta$-CD-(AuNRs)-CM; Group 4: DOX/RGD-PEG- $\beta$-CD-(AuNPs)-CMwith NIR irradiation $(808 \mathrm{~nm}, 800 \mathrm{~mW}$ ); Group 5: DOX/RGD-PEG- $\beta$-CD-CM with NIR irradiation $(808 \mathrm{~nm}, 800 \mathrm{~mW})$; Group 6 : DOX/mPEG- $\beta$-CD-CM with NIR irradiation $(808 \mathrm{~nm}, 800 \mathrm{~mW})$; Group 7:DOX.HCl; Group 8: saline; Group 9: saline with NIR irradiation ( $808 \mathrm{~nm}, 800 \mathrm{~mW}$ ). The dose of DOX was $5 \mathrm{mg} / \mathrm{kg}, \mathrm{p}$ values at 27 days $(*: \mathrm{P}<0.05$; **: $\mathrm{P}<0.01 ; * * *: \mathrm{P}<0.001)$.

The in vivo therapeutic efficacy of DOX-loaded nanoparticles $(5 \mathrm{mg} / \mathrm{kg})$ on tumor-bearing mice was studied (Figure 7A). Ten male BALB/c mice bearing $4 \mathrm{~T} 1$ breast cancers with the tumor volume of $100-200 \mathrm{~mm}^{3}$ in the right flank were used in each group, the volume of tumors were within the penetration depth of NIR irradiation.[46] All the groups were injected with DOX-loaded nanoparticles via the tail vein. At $2 \mathrm{~h}$ post-injection, the tumor bearing mice were exposed to NIR irradiation for $5 \mathrm{~min}$. The groups of saline and saline with NIR irradiation were used as the controls. Obviously, the group of DOX/RGD-PEG- $\beta$-CD-(AuNRs)-CM nanoparticles with NIR laser irradiation ( $808 \mathrm{~nm}, 800 \mathrm{~mW}$ ) (Group 1) showed the best inhibition efficacy on cancer growth within all the nine groups. Most tumors in this group stopped growing entirely after ten days, leaving black scars in the original tumor sites (Figure S7). Photothermal therapy induced by NIR illumination is an emerging and effective tool in cancer therapy [47]. Because of small light scattering and absorption from Au and intrinsic chromophores in tissues, NIR light could 
penetrate tissues with sufficient intensity and high spatial precision [48-50]. The group of DOX/RGD-PEG- $\beta$-CD-(AuNRs)-CM nanoparticles with NIR laser irradiation (808 nm, $400 \mathrm{~mW}$ ) (Group 2) also showed efficient inhibition effect on tumor growth. The in vivo anticancer activity of these two groups was better than that of free DOX $\cdot \mathrm{HCl}$ (Group 1 vs free DOX $\cdot \mathrm{HCl}, \mathrm{P}<0.01$ **; Group 2 vs free DOX·HCl, $\mathrm{P}<0.01 * *)$. There was also significant difference between Group 1 and Group $2(\mathrm{P}<0.05 *)$. Moreover, the tumor growth inhibition efficiency of these two groups were much better than that of DOX/RGD-PEG- $\beta$-CD-(AuNRs)-CM nanoparticles without NIR irradiation (Group 3). These results revealed that NIR irradiation could promote the anticancer activity of drug loaded nanoparticles in vivo. In addition, the higher power NIR irradiation led to better inhibition rate. The inhibition efficiency of DOX/RGD-PEG- $\beta$-CD-(AuNPs)-CM nanoparticles $(808 \mathrm{~nm}, 800 \mathrm{~mW}$ ) (Group 4) was comparable to that of free DOX $\cdot \mathrm{HCl}$, which was lower than that of Group 1 as AuNRs exhibited better photothermal effect to AuNPs. [51] This result was in agreement with the anticancer activity in vitro. The tumor inhibition rate of DOX/RGD-PEG- $\beta$-CD-CM (Group 5) was much better that that of DOX/mPEG- $\beta$-CD-CM (Group 6) for the targeting moiety cRGD in Group 5.

Body weight shift was regarded as the measurement of drug tolerability and degree of systemic toxicity. The body weights of all nine groups were monitored throughout the experimental time. The DOX/nanoparticles and saline groups showed little body weight shift, which suggested that the mice had better drug tolerability to the formulations. The maximum of $\sim 20 \%$ body weight decrease shift was observed during the treatment of 12 days in free $\mathrm{DOX} \cdot \mathrm{HCl}$ formulation group, indicating serious systemic toxicity of free DOX $\cdot \mathrm{HCl}$. During the treatment, mice administrated with DOX-loaded nanoparticles showed no significant difference in body weight loss versus saline, while the free DOX $\cdot \mathrm{HCl}$ formulation exhibited significant difference to other formulations $(\mathrm{P}<$ $0.01 * * *)$. These results revealed that the encapsulation of nanoparticles could greatly reduce the systemic toxicity of DOX (Figure 7B).

The survival rates of the mice treated with the nine formulations were measured (Figure7C). All the mice administrated with DOX loaded nanoparticles were survival within the whole experimental time of 27 days, however, $40 \%$ mice in free $\mathrm{DOX} \cdot \mathrm{HCl}$ group died within 21 days. The survival rates in the groups containing AuNRs/AuNPs and RGD with NIR laser irradiation were much higher than those of other groups, which implied that nanoparticles containing AuNRs or AuNPs and cRGD moieties with NIR irradiation would reduce systemic toxicity of anticancer drug and enhance therapeutic efficacy in vivo. 


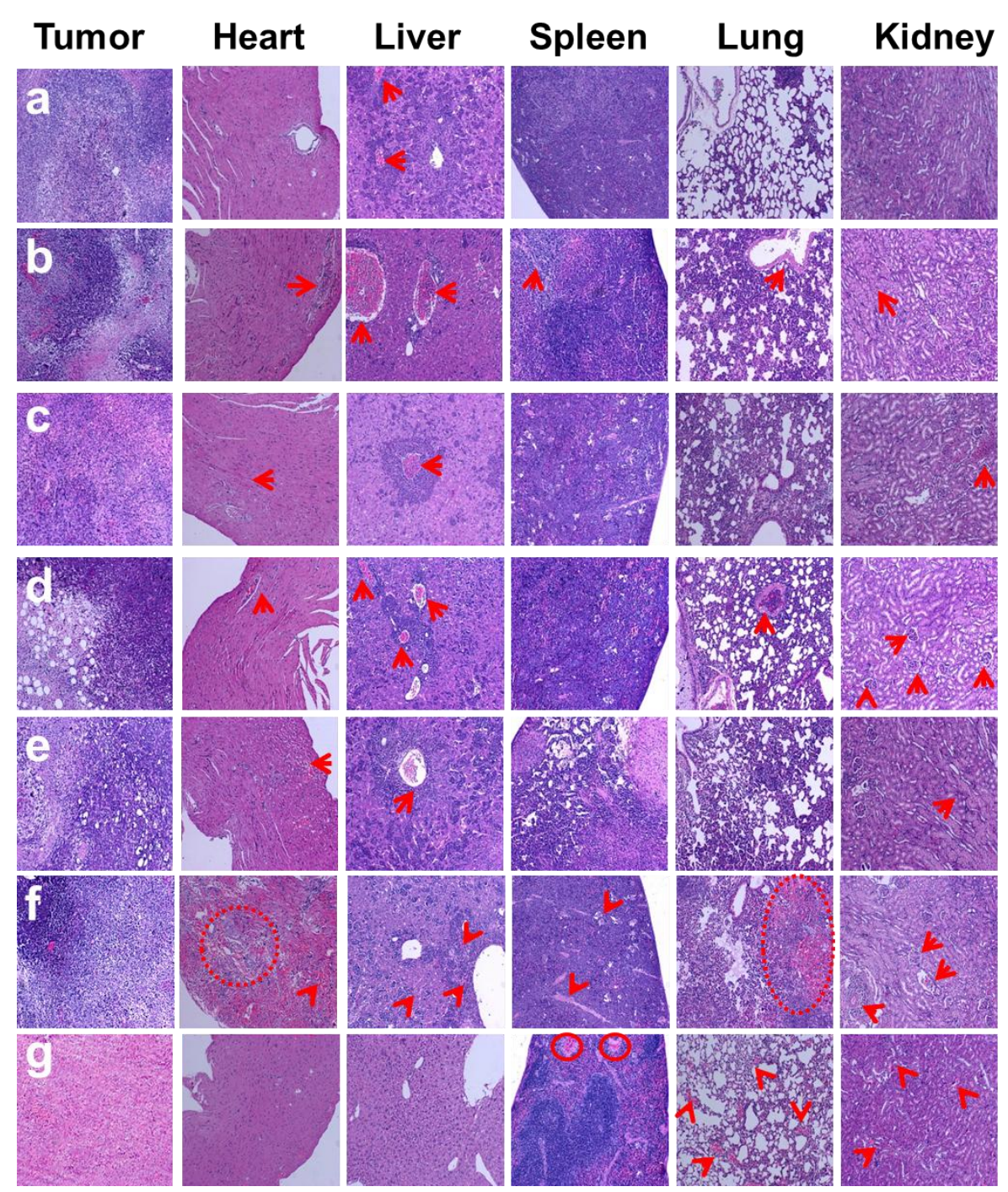

Figure 8. Histological analysis of different organs in tumor-bearing mice, a: DOX/RGD-PEG- $\beta$-CD-(AuNRs)-CM with NIR irradiation $(808 \mathrm{~nm}, 800 \mathrm{~mW}) ; \quad$ b: DOX/RGD-PEG- $\beta$-CD-(AuNRs)-CM with NIR irradiation $(808 \mathrm{~nm}, 400 \mathrm{~mW}) ; \quad$ : DOX/RGD-PEG- $\beta$-CD-(AuNPs)-CM with NIR irradiation $(808 \mathrm{~nm}, \quad 800 \mathrm{~mW}) ; \quad \mathrm{d}$ : DOX/RGD-PEG- $\beta$-CD-CM with NIR irradiation $(808 \mathrm{~nm}, 800 \mathrm{~mW})$; e: DOX/mPEG- $\beta$-CD-CM with NIR irradiation ( $808 \mathrm{~nm}, 800 \mathrm{~mW}$ ); f: DOX· HCl; g: saline. The dose of DOX was $5 \mathrm{mg} / \mathrm{kg}$.

After 30 day treatment, the mice in all groups were randomly picked out to be sacrificed. Major organs from each mouse were taken out, fixed in $4 \%$ formaldehyde, processed routinely into paraffin, sectioned, stained with hematoxylin and eosin (H\&E), and examined by a digital microscope. The examined tissues included tumor, heart, liver, spleen, lung and kidney (Figure 8). The groups of DOX/RGD-PEG- $\beta$-CD-(AuNRs)-CM with NIR irradiation ( $808 \mathrm{~nm}, 800 \mathrm{~mW}$ ), DOX/RGD-PEG- $\beta$-CD-(AuNRs)-CM with NIR irradiation $(808 \mathrm{~nm}, 400 \mathrm{~mW})$ and DOX.HCl formulations exhibited much better tumor inhibition effect (tumor images in $a, b$ and $f$ ) as tumor necrosis with hemorrhage appeared in most areas. However, compared to the two nanoparticles formulations, free DOX. $\mathrm{HCl}$ led to serious heart toxicity as necrosis (heart image in f) was 
observed with acute inflammatory cells in filtration in epicardium and congestion between myocardial cells. Simultaneously, in saline group, little necrosis (tumor image in g) area in the center of neoplastic cells was observed. The DOX-loaded nanoparticles groups reduced liver inflammation though the liver was usually accompanied by inflammation and hyperemia. White pulp atrophy, congestion and splenic corpuscle disappearance were observed in spleen (spleen images in $\mathrm{f}$ and $\mathrm{g}$ ). Pulmonary hemorrhage was observed in lung (lung images in $\mathrm{f}$ ) and multifocal metastases of cancer in serosa of lung were observed in lung (lung images in $f$ and g). Glomerular swelling in the renal capsule was shrinking or disappearing in kidney (kidney images in $\mathrm{f}$ and $\mathrm{g}$ ). Other groups were in weak inflammation. All the organs of heart, liver, spleen, lung and kidney in nanopartilces formulations groups were normal in the histological tissue slides, indicating the non-toxicity of these formulations to organs.
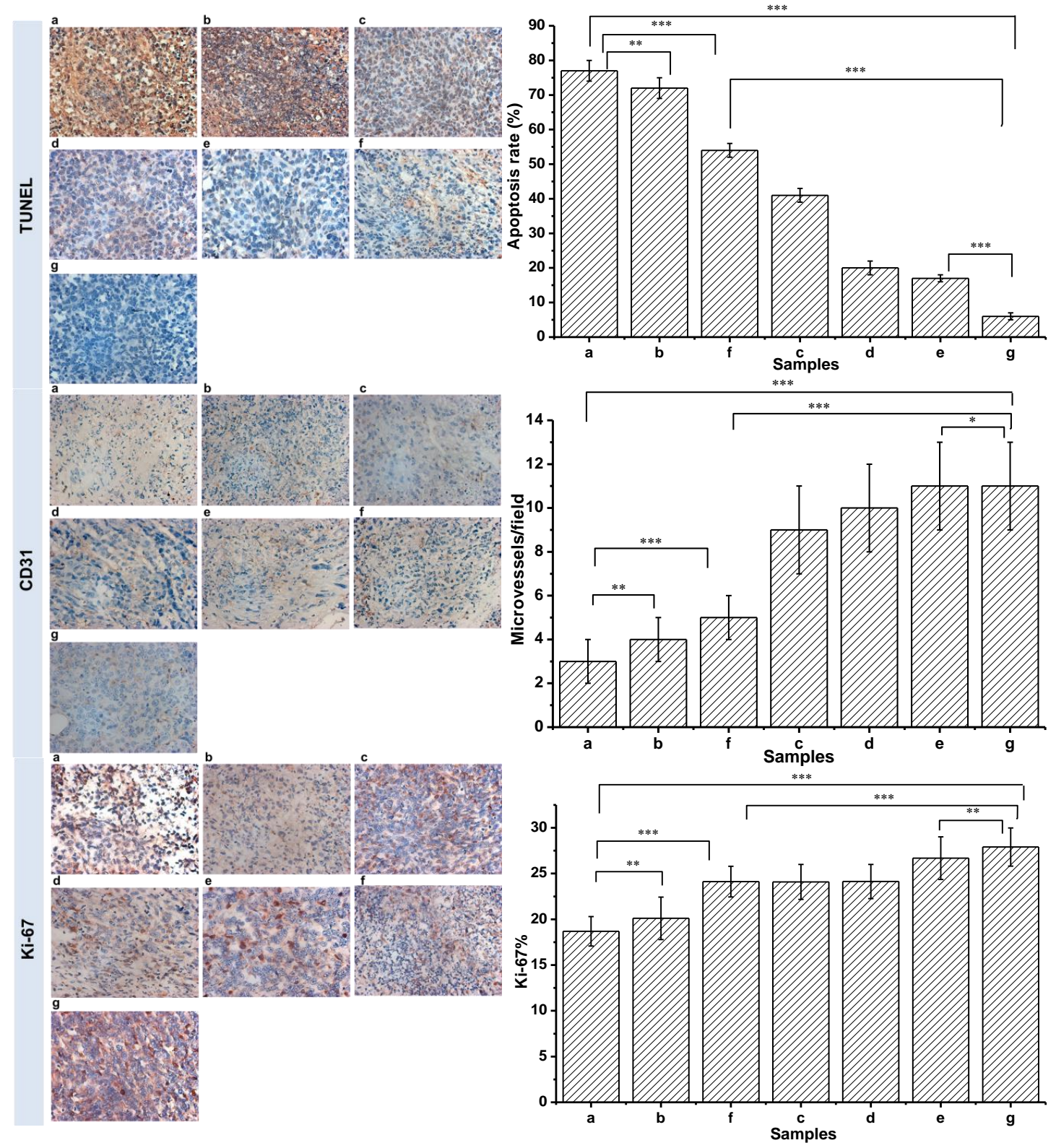
Figure 9. The TUNEL, Ki-67 and CD31 immunohistochemical (IHC) staining of tumor tissues (x 400). The brown areas indicate TUNEL-positive, CD31-positive or Ki-67-positive staining, a: DOX/RGD-PEG- $\beta$-CD-(AuNRs)-CM with NIR irradiation $(808 \mathrm{~nm}, \quad 800 \mathrm{~mW}), \quad$ b: DOX/RGD-PEG- $\beta$-CD-(AuNRs)-CM with NIR irradiation $(808 \mathrm{~nm}, 400 \mathrm{~mW}), \quad$ : DOX/RGD-PEG- $\beta$-CD-(AuNPs)-CM with $\quad$ NIR irradiation $\quad(808 \quad \mathrm{~nm}, \quad 800 \mathrm{~mW}), \quad \mathrm{d}$ : DOX/RGD-PEG- $\beta$-CD-CM with NIR irradiation $(808 \mathrm{~nm}, 800 \mathrm{~mW})$, e: DOX/mPEG- $\beta$-CD-CM with NIR irradiation $(808 \mathrm{~nm}, 800 \mathrm{~mW})$, f: DOX $\cdot \mathrm{HCl}$, and g: saline. The apoptotic index was calculated as the ratio of the apoptotic cell number to the total tumor cell number in each field of view. The CD31 positive area was expressed in endothelial cell pack and count capillary number by reading each section (MVD). The Ki-67 density in each image was calculated by Ki-67-positive area to total area. Data were presented as mean $\pm \mathrm{SD}(\mathrm{n}=5)(*: \mathrm{P}<0.05$; **: $\mathrm{P}<0.01 ; * * * \mathrm{P}<0.001)$. The dose of DOX was $5 \mathrm{mg} / \mathrm{kg}$.

The tumors were taken out from the treated mice at the end of the trials, immunohistochemical studies were performed for further investigation of antitumor efficacy and tumor suppression mechanism.[52] The terminal deoxynucleotidyl transferase-mediated dUTP nick end labeling (TUNEL) assay was detected apoptosis in situ, both the CD31 and the Ki-67 antigen staining were performed to assess the antitumor efficacy on tumor cell proliferation. Consistent with the in vivo antitumor efficacy studies, the tumor tissues of the mice treated with DOX/RGD-PEG- $\beta$-CD-(AuNRs)-CM $(5 \mathrm{mg} / \mathrm{kg})$ with NIR irradiation $(808 \mathrm{~nm}, 800 \mathrm{~mW})$ showed the highest apoptosis rate of 77\%, the least number of microvessel density (MVD) and the lowest level of Ki-67 positive cells (Figure 9). The DOX-loaded nanoparticles exhibited significant differences to the group of saline. The results demonstrated that the DOX-loaded nanoparticles could effectively inhibit the proliferation and induce the apoptosis of tumor cells.

Moreover, blood routine examinations were investigated including white blood cell count (WBC), red blood cell count (RBC) and blood platelet count (PLT) (Table S1). The WBC results suggested that the DOX-loaded nanoparticles exhibited better inhibition effect on inflammation as the WBC values of all the groups from Sample 2 to 5 were in the normal range. The RBC values of all groups were in normal range. However, the PLT in the group of saline was higher than normal range due to the severe inflammation and bleeding symptoms in this group.[53] These results indicated that the DOX-loaded nanoparticles exhibited no obvious damage to blood cells.

\section{Conclusion}

A NIR light sensitive coumarin derivative chromophore of7-(diethylamino)-4-(hydroxymethyl)-2H-chromen-2-one (DEACM) moiety was incorporated on $\beta$-cyclodextrins with the modification of cRGD functionalized PEG and Au nanorods, the conjugates were fabricated hybrid nanoparticles to load anticancer drug doxorubicin. Irradiated by the NIR light with the wavelength of $808 \mathrm{~nm}$, the photosolvolysis of DEACM triggered the accelerated release of anticancer drug. The Au nanorods in the nanoparticles enhanced the NIR 
absorbance to promote the photosolvolysis. Both in vitro and in vivo anticancer activity tests of the DOX-loaded nanoparticles revealed that the NIR-sensitive RGD-PEG- $\beta$-CD-(AuNRs)-CM hybrid nanoparticles exhibited promising therapeutic efficacy to cancers with the combination of chemtherapy and hyperthemia therapy.

\section{Acknowledgement}

The authors thank for the financial support of National Science Foundation of China (No. 51573111, 51222304, 21202122), Program for Changjiang Scholars and Innovative Research Team in University (IRT_15R48), Ministry of Education of China (No.20130181110038) and the Natural Science Foundation of Zhejiang Province (LY15B020001).

\section{Reference}

[1] Srinivasarao M, Galliford CV, Low PS. Principles in the design of ligand-targeted cancer therapeutics and imaging agents. Nat Rev Drug Discov. 2015;14:203-219.

[2] Huang P, Wang D, Su Y, Huang W, Zhou Y, Cui D, Zhu X, Yan D. Combination of Small Molecule Prodrug and Nanodrug Delivery: Amphiphilic Drug-Drug Conjugate for Cancer Therapy. J Am Chem Soc. 2014;136:11748-11756.

[3] Damaghi M, Tafreshi NK, Lloyd MC, Sprung R, Estrella V, Wojtkowiak JW, Morse DL, Koomen JM, Bui MM, Gatenby RA, Gillies RJ. Chronic acidosis in the tumour microenvironment selects for overexpression of LAMP2 in the plasma membrane. Nat Commun. 2015;6:8752-8764.

[4] Webb BA, Chimenti M, Jacobson MP, Barber DL. Dysregulated pH: a perfect storm for cancer progression. Nat Rev Cancer. 2011;11:671-677.

[5] Chang C-H, Qiu J, O'Sullivan D, Buck Michael D, Noguchi T, Curtis Jonathan D, Chen Q, Gindin M, Gubin Matthew M, van der Windt Gerritje JW, Tonc E, Schreiber Robert D, Pearce Edward J, Pearce Erika L. Metabolic Competition in the Tumor Microenvironment Is a Driver of Cancer Progression. Cell. 2015;162:1229-1241.

[6] Brandl F, Bertrand N, Lima EM, Langer R. Nanoparticles with photoinduced precipitation for the extraction of pollutants from water and soil. Nat Commun. 2015;6:7765-7774.

[7] Chen Y-P, Chen C-T, Hung Y, Chou C-M, Liu T-P, Liang M-R, Chen C-T, Mou C-Y. A New Strategy for Intracellular Delivery of Enzyme Using Mesoporous Silica Nanoparticles: Superoxide Dismutase. J Am Chem Soc. 2013;135:1516-1523.

[8] Nguyen MM, Carlini AS, Chien M-P, Sonnenberg S, Luo C, Braden RL, Osborn KG, Li Y, Gianneschi NC, Christman KL. Enzyme-Responsive Nanoparticles for Targeted Accumulation and Prolonged Retention in Heart Tissue after Myocardial Infarction. Adv Mater. 2015;27:5547-5552.

[9] Chen Q, Liu X, Chen J, Zeng J, Cheng Z, Liu Z. A Self - Assembled Albumin - Based Nanoprobe for In Vivo Ratiometric Photoacoustic pH Imaging. Adv Mater. 2015;27:6820-6827

[10] Sun C-Y, Shen S, Xu C-F, Li H-J, Liu Y, Cao Z-T, Yang X-Z, Xia J-X, Wang J. Tumor Acidity-Sensitive Polymeric Vector for Active Targeted siRNA Delivery. J Am Chem Soc. 2015;137:15217-15224.

[11] Shanmugam V, Selvakumar S, Yeh C-S. Near-infrared light-responsive nanomaterials in cancer therapeutics. Chem Soc Rev. 2014;43:6254-6287.

[12] He Q, Kiesewetter DO, Qu Y, Fu X, Fan J, Huang P, Liu Y, Zhu G, Liu Y, Qian Z, Chen X. NIR-Responsive On-Demand Release of CO from Metal Carbonyl-Caged Graphene Oxide Nanomedicine. Adv Mater. 2015;27:6741-6746.

[13] Barch M, Okada S, Bartelle BB, Jasanoff A. Screen-Based Analysis of Magnetic Nanoparticle Libraries 
Formed Using Peptidic Iron Oxide Ligands. J Am Chem Soc. 2014;136:12516-12519.

[14] Qu D-H, Wang Q-C, Zhang Q-W, Ma X, Tian H. Photoresponsive Host-Guest Functional Systems. Chem Rev. 2015;115:7543-7588.

[15] Yuan Y, Liu J, Liu B. Conjugated-Polyelectrolyte-Based Polyprodrug: Targeted and Image-Guided Photodynamic and Chemotherapy with On-Demand Drug Release upon Irradiation with a Single Light Source. Angew Chem Int Ed. 2014;53:7163-7168.

[16] Liu Y, Liu Y, Bu W, Cheng C, Zuo C, Xiao Q, Sun Y, Ni D, Zhang C, Liu J, Shi J. Hypoxia Induced by Upconversion-Based Photodynamic Therapy: Towards Highly Effective Synergistic Bioreductive Therapy in Tumors. Angew Chem Int Ed. 2015;54:8105-8109.

[17] Pu K, Shuhendler AJ, Jokerst JV, Mei J, Gambhir SS, Bao Z, Rao J. Semiconducting polymer nanoparticles as photoacoustic molecular imaging probes in living mice. Nat Nanotechnol. 2014;9:233-239

[18] Fedoryshin LL, Tavares AJ, Petryayeva E, Doughan S, Krull UJ. Near-Infrared-Triggered Anticancer Drug Release from Upconverting Nanoparticles. ACS Appl Mater Interfaces. 2014;6:13600-13606.

[19] Deng H, Dai F, Ma G, Zhang X. Theranostic Gold Nanomicelles made from Biocompatible Comb - like Polymers for Thermochemotherapy and Multifunctional Imaging with Rapid Clearance. Adv Mater. 2015;27:3645-3653.

[20] Lozano N, Al-Jamal WT, Taruttis A, Beziere N, Burton NC, Van den Bossche J, Mazza M, Herzog E, Ntziachristos V, Kostarelos K. Liposome-gold nanorod hybrids for high-resolution visualization deep in tissues. J Am Chem Soc. 2012;134:13256-13258

[21] Savage N. Synthetic coatings: Super surfaces. Nature. 2015;519:S7-S9.

[22] Smith NI, Mochizuki K, Niioka H, Ichikawa S, Pavillon N, Hobro AJ, Ando J, Fujita K, Kumagai Y. Laser-targeted photofabrication of gold nanoparticles inside cells. Nat Commun. 2014;5:5144-5152.

[23] Zeigler MB, Sun W, Rong Y, Chiu DT. Hybrid semiconducting polymer nanoparticles as polarization-sensitive fluorescent probes. J Am Chem Soc. 2013;135:11453-11456

[24] Wang J, Zhao J, Li Y, Yang M, Chang Y-Q, Zhang J-P, Sun Z, Wang Y. Enhanced Light Absorption in Porous Particles for Ultra-NIR-Sensitive Biomaterials. ACS Macro Lett. 2015;4:392-397

[25] Feng Y, Dai C, Lei J, Ju H, Cheng Y. Silole-Containing Polymer Nanodot: An Aqueous Low-Potential Electrochemiluminescence Emitter for Biosensing. Anal Chem. 2016;88:845-850.

[26] Raghupathi KR, Guo J, Munkhbat O, Rangadurai P, Thayumanavan S. Supramolecular Disassembly of Facially Amphiphilic Dendrimer Assemblies in Response to Physical, Chemical, and Biological Stimuli. Acc Chem Res. 2014;47:2200-2211

[27] Guardado-Alvarez TM, Sudha Devi L, Russell MM, Schwartz BJ, Zink JI. Activation of snap-top capped mesoporous silica nanocontainers using two near-infrared photons. J Am Chem Soc. 2013;135:14000-14003

[28] Babin J, Pelletier M, Lepage M, Allard JF, Morris D, Zhao Y. A New Two - Photon - Sensitive Block Copolymer Nanocarrier. Angew Chem Int Ed. 2009;48:3329-3332

[29] Liang Y, Deng X, Zhang L, Peng X, Gao W, Cao J, Gu Z, He B. Terminal modification of polymeric micelles with pi-conjugated moieties for efficient anticancer drug delivery. Biomaterials. 2015;71:1-10.

[30] Miao T, Fenn SL, Charron PN, Oldinski RA. Self-Healing and Thermoresponsive Dual-Cross-Linked Alginate Hydrogels Based on Supramolecular Inclusion Complexes. Biomacromolecules. 2015;16:3740-3750.

[31] Shuai X, Ai H, Nasongkla N, Kim S, Gao J. Micellar carriers based on block copolymers of poly(E-caprolactone) and poly(ethylene glycol) for doxorubicin delivery. J Controlled Release. 2004;98:415-426.

[32] Gao W, Lin X, Lin X, Ding J, Huang X, Wu H. Preparation of nano-sized flake carboxymethyl cassava starch under ultrasonic irradiation. Carbohydr Polym. 2011;84:1413-1418

[33] Zhou T, Yu M, Zhang B, Wang L, Wu X, Zhou H, Du Y, Hao J, Tu Y, Chen C. Inhibition of Cancer Cell 
Migration by Gold Nanorods: Molecular Mechanisms and Implications for Cancer Therapy. Adv Funct Mater. 2014;24:6922-6932

[34] Liu J, Yu M, Zhou C, Yang S, Ning X, Zheng J. Passive tumor targeting of renal-clearable luminescent gold nanoparticles: long tumor retention and fast normal tissue clearance. J Am Chem Soc. 2013;135:4978-4981

[35] Kazunori K, Glenn S K, Masayuki Y, Teruo O, Yasuhisa S. Block copolymer micelles as vehicles for drug delivery. J Controlled Release. 1993;24:119-132.

[36] Deng X, Liang Y, Peng X, Su T, Luo S, Cao J, Gu Z, He B. A facile strategy to generate polymeric nanoparticles for synergistic chemo-photodynamic therapy. Chem Commun. 2015;51:4271-4274.

[37] Ji W, Li N, Chen D, Qi X, Sha W, Jiao Y, Xu Q, Lu J. Coumarin-containing photo-responsive nanocomposites for NIR light-triggered controlled drug release via a two-photon process. J Mater Chem B. 2013;1:5942-5949.

[38] Lin Q, Bao C, Cheng S, Yang Y, Ji W, Zhu L. Target-activated coumarin phototriggers specifically switch on fluorescence and photocleavage upon bonding to thiol-bearing protein. J Am Chem Soc. 2012;134:5052-5055

[39] Liang Y, Peng X, Chen Y, Deng X, Gao W, Cao J, Chang J, Gu Z, He B. Chain length effect on drug delivery of chrysin modified mPEG-PCL micelles. RSC Adv. 2015;5:59014-59021.

[40] Schmidt R, Geissler D, Hagen V, Bendig J. Mechanism of photocleavage of (coumarin-4-yl) methyl esters. J Phys Chem A. 2007;111:5768-5774

[41] Huang P, Lin J, Li W, Rong P, Wang Z, Wang S, Wang X, Sun X, Aronova M, Niu G, Leapman RD, Nie Z, Chen X. Biodegradable Gold Nanovesicles with an Ultrastrong Plasmonic Coupling Effect for Photoacoustic Imaging and Photothermal Therapy. Angew Chem. 2013;125:14208-14214.

[42] Lin J, Wang S, Huang P, Wang Z, Chen S, Niu G, Li W, He J, Cui D, Lu G, Chen X, Nie Z. Photosensitizer-Loaded Gold Vesicles with Strong Plasmonic Coupling Effect for Imaging-Guided Photothermal/Photodynamic Therapy. ACS Nano. 2013;7:5320-5329.

[43] Choi WI, Kim J-Y, Kang C, Byeon CC, Kim YH, Tae G. Tumor Regression In Vivo by Photothermal Therapy Based on Gold-Nanorod-Loaded, Functional Nanocarriers. ACS Nano. 2011;5:1995-2003.

[44] Kalluru P, Vankayala R, Chiang CS, Hwang KC. Nano-graphene oxide-mediated In vivo fluorescence imaging and bimodal photodynamic and photothermal destruction of tumors. Biomaterials. 2016;95:1-10.

[45] Li Z, Huang H, Tang S, Li Y, Yu XF, Wang H, Li P, Sun Z, Zhang H, Liu C, Chu PK. Small gold nanorods laden macrophages for enhanced tumor coverage in photothermal therapy. Biomaterials. 2016;74:144-154.

[46] Zhang C, Wang S, Xiao J, Tan X, Zhu Y, Su Y, Cheng T, Shi C. Sentinel lymph node mapping by a near-infrared fluorescent heptamethine dye. Biomaterials. 2010;31:1911-1917.

[47] Wang BK, Yu XF, Wang JH, Li ZB, Li PH, Wang H, Song L, Chu PK, Li C. Gold-nanorods-siRNA nanoplex for improved photothermal therapy by gene silencing. Biomaterials. 2016;78:27-39.

[48] Castrén - Persons M, Schröder T, Rämö OJ, Puolakkainen P, Lehtonen E. Contact Nd: YAG laser potentiates the tumor cell killing effect of hyperthermia. Lasers Surg Med. 1991;11:595-600

[49] Huff TB, Tong L, Zhao Y, Hansen MN, Cheng J-X, Wei A. Hyperthermic effects of gold nanorods on tumor cells. 2007.

[50] Chen WR, Adams RL, Carubelli R, Nordquist RE. Laser-photosensitizer assisted immunotherapy: a novel modality for cancer treatment. Cancer Lett. 1997;115:25-30

[51] Zhang Z, Wang J, Chen C. Gold Nanorods Based Platforms for Light-Mediated Theranostics. Theranostics. 2013;3:223-238.

[52] Li N, Li N, Yi Q, Luo K, Guo C, Pan D, Gu Z. Amphiphilic peptide dendritic copolymer-doxorubicin nanoscale conjugate self-assembled to enzyme-responsive anti-cancer agent. Biomaterials. 2014;35:9529-9545.

[53] Yuan A, Qiu X, Tang X, Liu W, Wu J, Hu Y. Self-assembled PEG-IR-780-C13 micelle as a targeting, safe and highly-effective photothermal agent for in vivo imaging and cancer therapy. Biomaterials. 2015;51:184-193. 